\title{
The Analysis of the General Performance and Mechanical Behavior of Unirradiated FeCrAl Alloys Before and After Welding
}

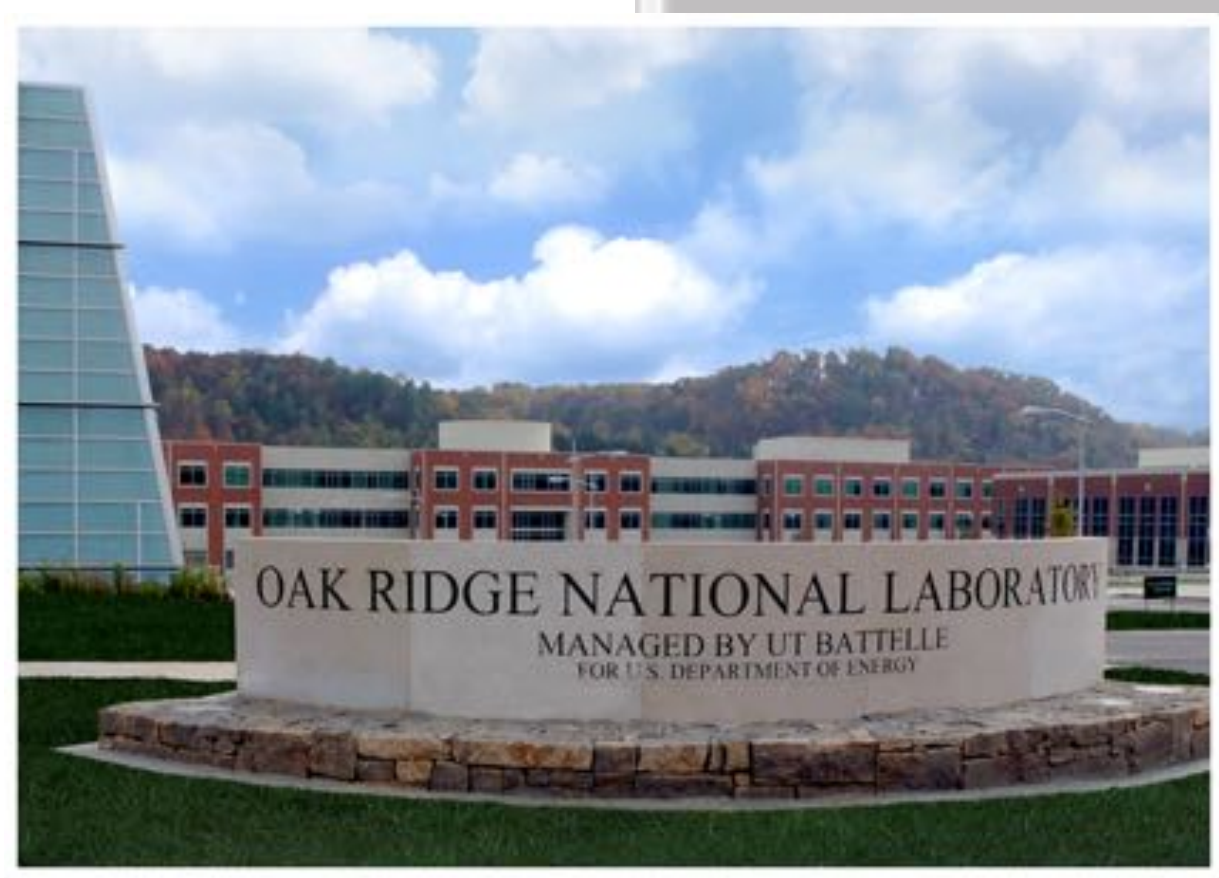

Maxim N. Gussev

Kevin G. Field

Yukinori Yamamoto

June 3, 2016 


\section{DOCUMENT AVAILABILITY}

Reports produced after January 1, 1996, are generally available free via US Department of Energy (DOE) SciTech Connect.

Website http://www.osti.gov/scitech/

Reports produced before January 1, 1996, may be purchased by members of the public from the following source:

National Technical Information Service

5285 Port Royal Road

Springfield, VA 22161

Telephone 703-605-6000 (1-800-553-6847)

TDD 703-487-4639

Fax 703-605-6900

E-mail info@ntis.gov

Website http://www.ntis.gov/help/ordermethods.aspx

Reports are available to DOE employees, DOE contractors, Energy Technology Data Exchange representatives, and International Nuclear Information System representatives from the following source:

Office of Scientific and Technical Information

PO Box 62

Oak Ridge, TN 37831

Telephone 865-576-8401

Fax 865-576-5728

E-mail reports@osti.gov

Website http://www.osti.gov/contact.html

This report was prepared as an account of work sponsored by an agency of the United States Government. Neither the United States Government nor any agency thereof, nor any of their employees, makes any warranty, express or implied, or assumes any legal liability or responsibility for the accuracy, completeness, or usefulness of any information, apparatus, product, or process disclosed, or represents that its use would not infringe privately owned rights. Reference herein to any specific commercial product, process, or service by trade name, trademark, manufacturer, or otherwise, does not necessarily constitute or imply its endorsement, recommendation, or favoring by the United States Government or any agency thereof. The views and opinions of authors expressed herein do not necessarily state or reflect those of the United States Government or any agency thereof. 


\author{
Maxim N. Gussev \\ Kevin G. Field \\ Yukinori Yamamoto
}

Date Published: June 3, 2016

Prepared by

OAK RIDGE NATIONAL LABORATORY

Oak Ridge, TN 37831-6283

managed by

UT-BATTELLE, LLC

for the

US DEPARTMENT OF ENERGY

under contract DE-AC05-00OR22725 



\section{CONTENTS}

\section{Page}

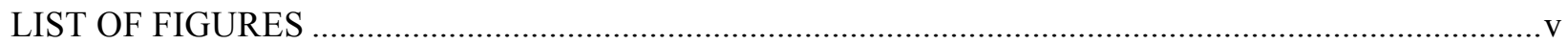

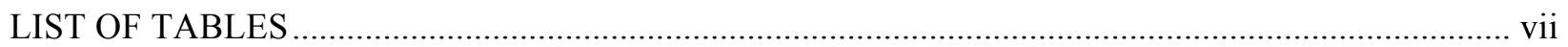

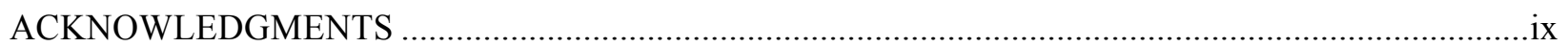

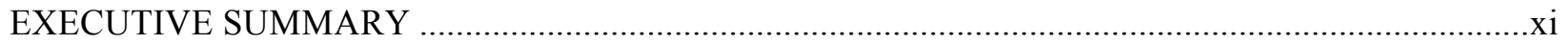

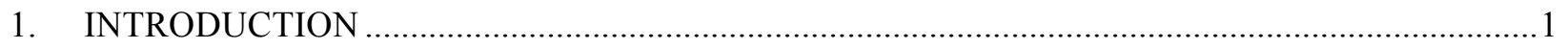

2. ALLOY DESIGN STRATEGY AND ELEMENT COMPOSITION .............................................

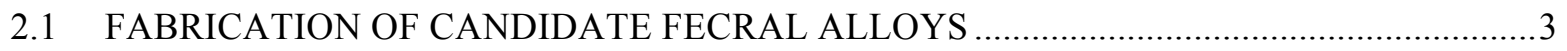

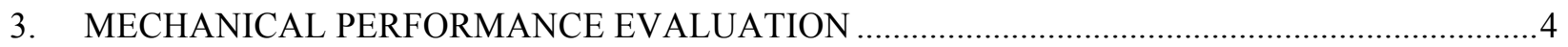

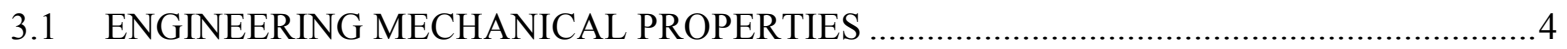

3.1.1 Properties of the As-received Alloys .......................................................................

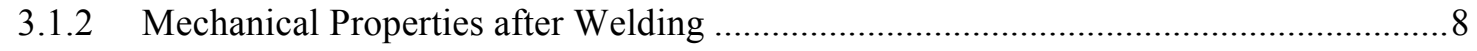

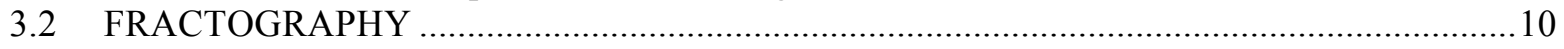

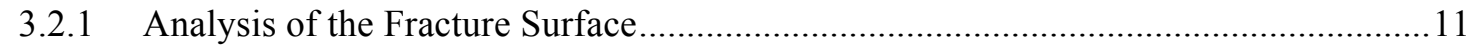

3.2.2 Detailed Analysis of Necking (Specimen Cross-section) in the Welded

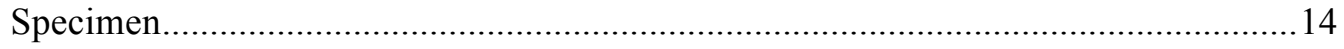

3.2.3 EBSD Scanning of the Near-fracture Region in HW26 .........................................16

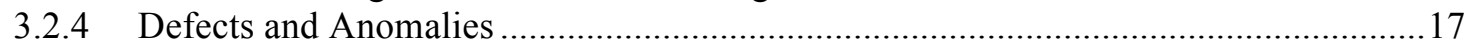

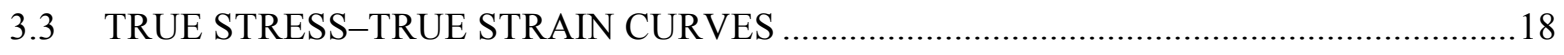

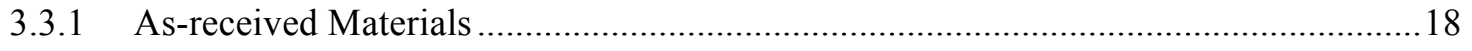

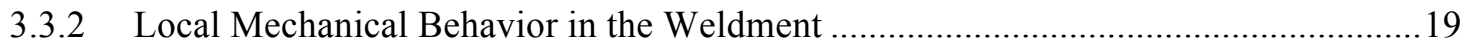

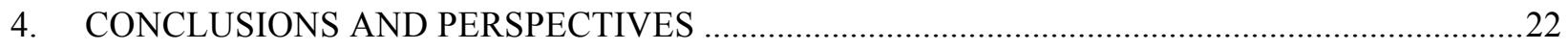

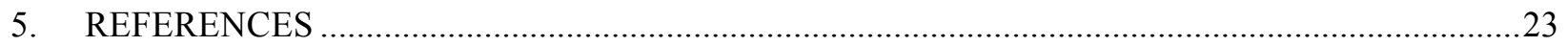





\section{LIST OF FIGURES}

Figure 1. The alloying scheme showing two main branches: alloying with metallic elements (left)

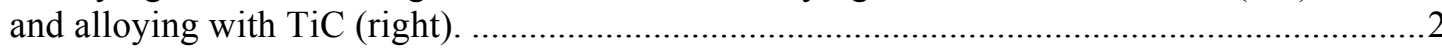

Figure 2. Composition effect on weldability and $\alpha$ '-phase formation in $\mathrm{FeCrAl}$ alloys............................. 3

Figure 3. Simplified schematic of the tensile specimen geometry used for mechanical testing. ..................5

Figure 4. Engineering tensile curves in "engineering stress, MPa-engineering plastic strain"

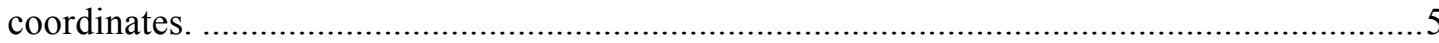

Figure 5. Engineering tensile curves in "engineering stress, $\mathrm{MPa}$ - engineering plastic strain"

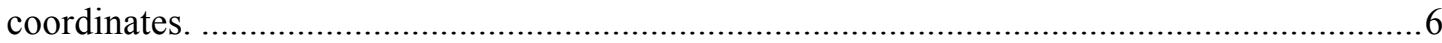

Figure 6. Comparison of the tensile behavior of the investigated alloys: left, ME-branch; right, TiC

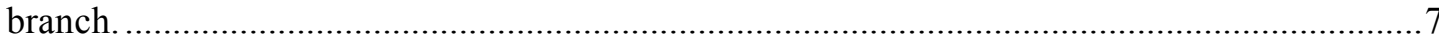

Figure 7. Engineering tensile diagrams in "plastic strain-engineering stress" coordinates for the asreceived ("AR", blue) and welded (red) specimens (ME-branch alloys). ................................9

Figure 8. Engineering tensile diagrams in "plastic strain-engineering stress" coordinates for the asreceived (blue) and welded (red) specimens (TiC-branch alloys).

Figure 9. Parent alloy: (left) SE imaging mode and (right) BSE imaging mode at a higher magnification of the fracture surface of the C35M alloy specimen.......................................11

Figure 10. The role of alloying and welding in the fracture mechanism (ME branch). ...........................12

Figure 11. The role of alloying and welding in the fracture mechanism (TiC branch) ..........................13

Figure 12. The general appearance of the fracture surface: as-received vs. welded. ...............................14

Figure 13. Cross-sectional view of the tensile specimen halves from Specimen ID HW26.....................15

Figure 14. Complex character of cracking and internal cracks in the weldment.....................................16

Figure 15. Strain-induced voids and small crack near the fracture point. ................................................16

Figure 16. Location of the EBSD scan and corresponding IPF map colored in the tensile direction. ........17

Figure 17. Misorientation profiles (point-to-origin type) showing a strong change in grain

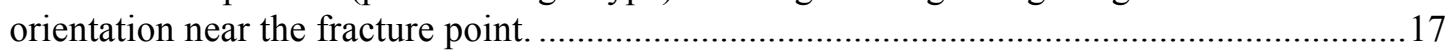

Figure 18. The internal flaw in one of the tensile specimens (ID: VW25, C37M after welding)..............18

Figure 19. Typical true stress-true strain curves for the investigated alloys..........................................19

Figure 20. Strain distribution along the C37M alloy specimen gauge before fracture; welded specimen (VW24) (Green-Lagrange strain tensor) ............................................................20

Figure 21. True strain-true stress curves for C37M alloy before and after welding ..............................20

Figure 22. Strain distribution along the C35M01TC (TiC-branch) alloy specimen gauge; welded specimen (VW24) (Green-Lagrange strain tensor)..............................................................21

Figure 23. True strain-true stress curves for TiC-branch alloys before and after welding. .......................22 



\section{LIST OF TABLES}

Table 1. Candidate FeCrAl alloys processing routes and composition in weight percentage ......................

Table 2. Mechanical properties of the modified alloys in as-received condition ...................................... 7

Table 3. Mechanical properties of the modified alloys after welding ….................................................

Table 4. Summary of the fracture mechanism for the investigated alloys............................................... 14 



\section{ACKNOWLEDGMENTS}

This research was sponsored by the US Department of Energy, Office of Nuclear Energy, for the Nuclear Energy Enabling Technologies (NEET) program for the Reactor Materials effort. This report was authored by UT-Battelle LLC under Contract No. DE-AC05-00OR22725 with the US Department of Energy. 



\section{EXECUTIVE SUMMARY}

The present report summarizes and discusses the preliminary results for the in-depth characterization of the modern, nuclear-grade $\mathrm{FeCrAl}$ alloys currently under development. The alloys were designed for enhanced radiation tolerance and weldability, and the research is currently being pursued by the Department of Energy (DOE) Nuclear Energy Enabling Technologies (NEET) program. Last year, seven candidate $\mathrm{FeCrAl}$ alloys with well-controlled chemistry and microstructures were designed and produced; welding was performed under well-controlled conditions.

The structure and general performance of unirradiated alloys were assessed using standardized and advanced microstructural characterization techniques and mechanical testing. The primary objective is to identify the best candidate alloy, or at a minimum to identify the contributing factors that increase the weldability and radiation tolerance of $\mathrm{FeCrAl}$ alloys, therefore enabling future generations of $\mathrm{FeCrAl}$ alloys to deliver better performance parameters. This report is structured so as to describe these critical assessments of the weldability; radiation tolerance will be reported on in later reports from this program.

Section 1 provides a brief overview of the $\mathrm{FeCrAl}$ alloy class as a nuclear technology, including their hypothesized benefits and the knowledge gaps that may exist. In particular, FeCrAl alloys are an attractive alloy class because of their response in nuclear power production environments such as hightemperature oxidation.

Section 2 briefly describes the alloy design strategy, including chemistry and microstructure control, and provides a detailed description of alloy composition.

Section 3 focuses on the alloy mechanical properties before and after welding. The changes in yield and ultimate stress, and uniform and total ductility, are discussed in detail. Mechanical behavior is analyzed focusing on tensile curves before and after welding. Alloying schemes did not have a negative effect on the performance of the alloys prior to welding. Also, it was established that the advanced alloys had a yield stress of $500 \mathrm{MPa}$ or more after welding, showing a significant advantage over the reference material ( $450 \mathrm{MPa}$ after welding). True stress-true strain curves were obtained and analyzed. The modified alloys did not show any signs of deformation hardening degradation. "Sudden fracture events" observed in the tensile tests were identified as a potential issue for the alloys with higher aluminum content ( $>5 \mathrm{wt} \%$ ) or with minor niobium additions; it appears these additions may be detrimental for the post-welding behavior.

Additionally, Section 3 discusses the fractography results. The appearance of brittle cleavage was a common issue for the investigated modified alloys. The fracture mode was fully brittle in the case of Aland $\mathrm{Nb}$ additions, making these modifications less preferable. Mixed fracture mode was observed in the materials with TiC additions.

The results and discussion presented in Sections 1-3 of the report are summarized and discussed in the conclusion. 



\section{INTRODUCTION}

Current and potential future nuclear power plant (NPP) designs call for materials that can withstand harsh and extreme environments: elevated temperature, acute and chronic corrosive media attack, and radiation. To withstand this demanding environment, a range of different materials and material classes are currently under development. One class of materials showing initial promise as new, robust materials for deployment in nuclear power production is the metallic, iron-based iron-chromium-aluminum (FeCrAl) alloy class. The $\mathrm{FeCrAl}$ alloy class is characterized as having a majority alloying percentage of $\mathrm{Fe}$ with additions of from several to tens of weight percent of $\mathrm{Cr}$ and $\mathrm{Al}$, resulting in a body-centered-cubic (BCC) crystal structure. This class of materials has shown excellent environmental compatibility, including resistance to aqueous corrosion, heavy metal compatibility, and oxidation resistance in high-temperature steam [1-4], as well as low radiation-induced swelling [5] and radiation responses on par with those of similar ferritic/martensitic steels [6,7].

Generally, FeCrAl alloys are a versatile class because they can be processed using several different techniques, including traditional wrought processing routes and more modern powder metallurgy. Additionally, wrought material has been shown to have the capability to form thin-walled tubes suitable for a cladding material in an NPP. However, several reports have indicated that $\mathrm{FeCrAl}$ alloys may be susceptible to cracking during welding. For example, Regina et al. [8] and Dupont et al. [9] have shown that $\mathrm{FeCrAl}$ weld overlays have a higher susceptibility to welding-induced cracking when high-Cr and/or high-Al variants are used. Such a lack of processability is significant, as many structures within current and future NPPs use welding to make final structures critical to the operation of the NPP.

Welding-induced cracking is a common degradation mode for many material classes. Luckily, it is easy to observe and mitigate during the production phase. A less readily (or rapidly) observed effect is the effect of radiation on weldments. Typically, nuclear-grade materials have highly tailored microstructures and microchemistries that enhance their radiation tolerance. The high heat input from fusion-based welding leads to localized melting of the material and inevitably the destruction or, at minimum, degradation of the tailored microstructure and microchemistry at the weld. Even in regions outside the fusion zone, localized heating can be at or above critical temperatures - for example, the critical temperature for recrystallization-leading to additional changes in microstructure. These regions are typically referred to as heat-affected-zones (HAZs). The result of the heating is very localized changes in microstructure and microchemistry, with gradients in effects as a function of the distance from the fusion zone.

Microstructural gradients lead to gradient-type changes in other properties, including the tensile or fracture properties of the weldment. Additionally, the localized changes in structure and chemistry mean changes in the features that affect radiation tolerance, such as grain size, dislocation density, and precipitate dispersions. The result is a part or weldment that is not optimized for radiation tolerance and a possible reduction in the service life of a weldment compared with a part that has not been welded.

Clearly, there is a need for investigation of the different degradation modes caused by welding before the welded $\mathrm{FeCrAl}$ components are used in any NPP. Unfortunately, there is limited research in this field, especially considering the ongoing development of nuclear-grade FeCrAls. To address this significant knowledge gap in FeCrAl alloy development, the US Department of Energy (DOE) initiated a research and development program in FY 2015 under the DOE Nuclear Energy Enabling Technologies program. The research centers on the use of candidate nuclear-grade $\mathrm{FeCrAl}$ alloys designed for enhanced weldability and radiation tolerance. Methods of achieving weldable but radiation-tolerant $\mathrm{FeCrAl}$ alloy were investigated using alloy refinement control. In particular, two different alloy refinement techniques were used: (1) control of the metallic alloying elements (primarily Al) and (2) the addition of precipitate dispersions into the matrix to reduce weld cracking susceptibility and promote better microstructural and microchemistry changes after welding. The result was a two-"branch" scheme: a metal (ME) alloying 
branch (alloys with $\mathrm{Al}$ or $\mathrm{Nb}$ additions) and a $\mathrm{TiC}$ branch (alloys with precipitate-TiC additions). This scheme is shown in Figure 1.

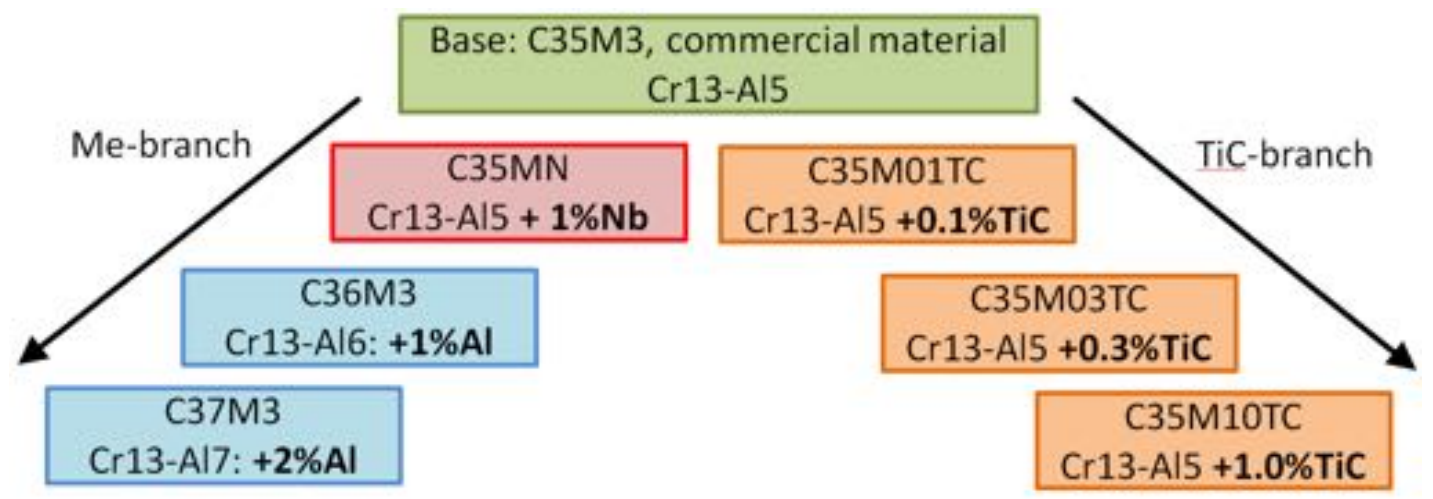

Figure 1. The alloying scheme showing two main branches: alloying with metallic elements (left) and alloying with $\mathrm{TiC}$ (right).

A base alloy designated as C35M3 - which can be considered the candidate closest to a commercial, nuclear-grade FeCrAl alloy at the start of this program - was used as the foundational alloy. The remaining alloys exist as distinguished variants from the $\mathrm{C} 35 \mathrm{M}$ grade, with their variations depending on the branch in which they exist. Further details on their processing and microstructure are presented in later sections of this report.

The ME branch primarily explores the effects of Al addition on both weld-induced cracking and the phase stability of the alloys under low- to moderate-dose irradiation. For example, Regina et al. [8] established a composition-based cracking boundary for $\mathrm{FeCrAl}$ alloys. Their data, reproduced in modified form in Figure 2, show that the base alloy $\mathrm{C} 35 \mathrm{M}$ exists close to, if not on, the cracking boundary. It happens by the possible circumstance that $\mathrm{C} 35 \mathrm{M}$ also sits nearly on the phase boundary for the formation of the Crrich $\alpha^{\prime}$ phase at moderate to low temperatures $\left(<475-500^{\circ} \mathrm{C}\right)$, as proposed by Kobayashi and Takasugi [10]. The formation of the Cr-rich $\alpha^{\prime}$ phase has been linked to significant hardening and embrittlement in aged and/or irradiated $\mathrm{FeCr}$ and $\mathrm{FeCrAl}$ alloys.

The $\alpha-\alpha^{\prime}$ phase boundary is also overlaid onto an image from Regina et al. to show the overlapping regions where the Cr-rich $\alpha^{\prime}$ phase is postulated to form under thermal aging and where cracked weldments are found. Note that the phase boundary proposed by Kobayashi and Takasugi was based on a change in the hardness of diffusion couple-like experiments after thermal aging at $475^{\circ} \mathrm{C}$. It is possible, even probable, that the phase boundary is inaccurate and that the regime is larger in Figure 2, as the Crrich $\alpha^{\prime}$ phase is known to have a low hardening coefficient [6] and may not contribute to hardening in low number densities and/or sizes. Hence, the C35M alloy could exist in the $\alpha-\alpha$ ' phase regime, as could the high-Al variants shown in Figure 2. Hence, the inclusion of the $\mathrm{C} 36 \mathrm{M}$ and $\mathrm{C} 37 \mathrm{M}$ alloys in the test matrix will explore the possible delicate balance between the phase boundary and the weld-induced cracking boundary. 


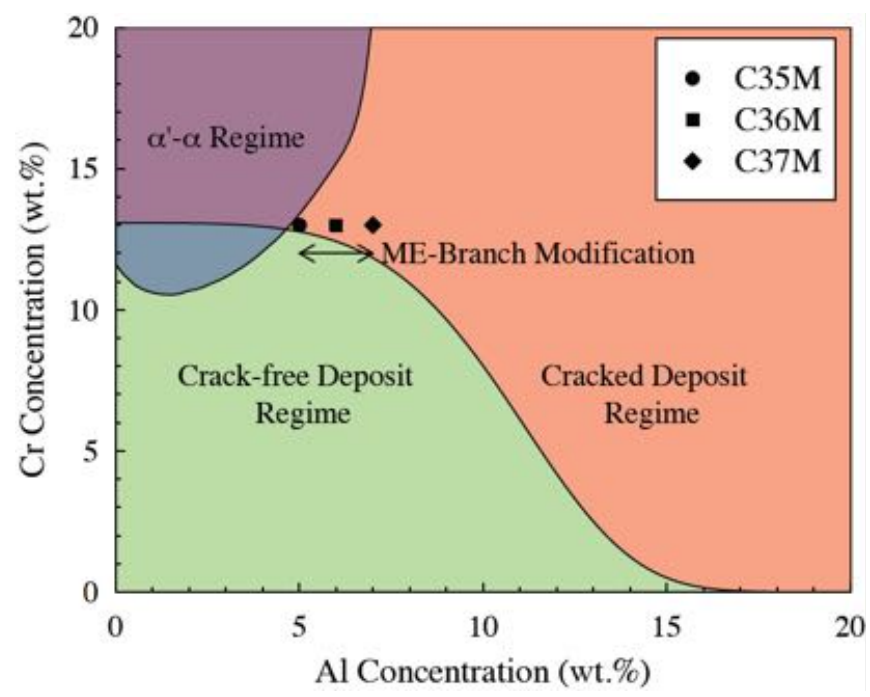

Figure 2. Composition effect on weldability and $\alpha$ '-phase formation in FeCrAl alloys. Regimes determined from Refs. $[8,10]$.

The other alloy in the ME branch, C35MN, includes niobium additions into the matrix to form Laves phase precipitates during typical processing routes. The $\mathrm{C} 35 \mathrm{MN}$ alloy refinement is similar to the TiC branch except that the addition was intrinsic and did not require special processing routes. In both cases, the precipitates, either Laves phase or $\mathrm{TiC}$, were added to the matrix microstructure to introduce benign hydrogen trapping sites. These sites (small carbide or Laves phase particles) have been shown initially to reduce welding-induced cracking [9]. They also could act as pinning sites during solidification and recrystallization during welding and hence have an inherent ability to help maintain the base microstructure in the weldment.

This report undertakes a critical assessment of the application of alloy refinement in FeCrAl alloys to increase the overall weldability of the alloys. The goal is to suggest what refinement techniques, if any, are preferred methods for reducing the weld-induced cracking susceptibility of the $\mathrm{FeCrAl}$ alloy class. Note that this report focuses only on the properties of unirradiated weldments and does not include data regarding the radiation tolerance of weldments. Radiation tolerance will be considered in a later publication.

The assessment of alloy refinement was completed by evaluating the tensile properties of the different alloys in each branch of the alloy refinement scheme in Figure 1. Modern techniques and applications were deployed, including digital image correlation (DIC) and electron microscopy, to provide a foundational database for the assessment. Based on this database, suggestions are provided for continued research on the different alloys currently under investigation in the program on Radiation Tolerance of Controlled Fusion Welds in High-Temperature Oxidation Resistant FeCrAl Alloys.

\section{ALLOY DESIGN STRATEGY AND ELEMENT COMPOSITION}

\subsection{FABRICATION OF CANDIDATE FECRAL ALLOYS}

As discussed in a previous report [11] and briefly in Section 2 of this report, a set of FeCrAl alloys were conceptualized and fabricated and are under assessment for use within this research and development 
program for candidate nuclear-grade $\mathrm{FeCrAl}$ alloys. The alloy sub-classes are $\mathrm{FeCrAl}$ alloys with high-Al additions (6-7 wt \% Al, designated as C36M and C37M), FeCrAl alloys with Laves precipitate dispersions (designated as $\mathrm{C} 35 \mathrm{MN}$ ), and $\mathrm{FeCrAl}$ alloys with $\mathrm{TiC}$ precipitate dispersions (designated as C35M01TC, C35M03TC, C35M10TC). (See Figure 1.) The alloys generated were all derivations of a primary candidate alloy designated as $\mathrm{C} 35 \mathrm{M}$. The $\mathrm{C} 35 \mathrm{M}$ alloy is a $\mathrm{FeCrAl}$ alloy with a nominal target composition of $\mathrm{Fe}-13 \mathrm{Cr}-5 \mathrm{Al}-2 \mathrm{Mo}-0.2 \mathrm{Si}-0.05 \mathrm{Y}$ in wt $\%$ and a ferritic matrix with grain sizes on the order of $5-10 \mu \mathrm{m}$.

Alloy production and basic structure, as well as preliminary results on the mechanical properties, are given in detail in Field et al. [11]. Table 1 provides the alloy compositions in the context of the present report; the modified alloys are discussed in terms of the two branches shown in Figure 1: the ME branch (with $\mathrm{Al}$ or $\mathrm{Nb}$ additions) and the $\mathrm{TiC}$ branch (with TiC additions).

Table 1. Candidate FeCrAl alloys processing routes and composition in weight percentage

\begin{tabular}{lccccccccccccc}
\hline \multicolumn{1}{c}{ Alloy } & Fe & Cr & Al & Y & Mo & Si & Nb & C & S & O & N & P & Ti \\
\hline C35M3 $^{1}$ & 79.43 & 13.06 & 5.31 & 0.053 & 2 & 0.13 & $<0.01$ & 0.001 & $<0.0003$ & 0.0012 & 0.0003 & 0.007 & $<0.01$ \\
C36M3 $^{1}$ & 78.8 & 12.98 & 6 & 0.04 & 1.98 & 0.18 & $<0.01$ & 0.003 & $<0.0003$ & 0.0016 & 0.0002 & $<0.002$ & 0.01 \\
C37M $^{1}$ & 77.49 & 13.01 & 7.22 & 0.081 & 1.99 & 0.19 & $<0.01$ & 0.001 & $<0.0003$ & 0.0026 & 0.0002 & 0.004 & $<0.01$ \\
C35MN6 $^{1}$ & 78.7 & 13 & 5.11 & 0.044 & 1.99 & 0.18 & 0.96 & 0.005 & 0.0003 & 0.0014 & 0.0002 & $<0.002$ & - \\
C35M01TC $^{2}$ & 79.51 & 13 & 5.2 & 0.04 & 1.98 & 0.15 & $<0.01$ & 0.024 & $<0.0003$ & 0.0009 & 0.0004 & 0.002 & 0.08 \\
C35M03TC $^{2}$ & 79.34 & 13.03 & 5.17 & 0.04 & 1.97 & 0.15 & $<0.01$ & 0.058 & $<0.0003$ & 0.0009 & 0.0003 & 0.003 & 0.22 \\
C35M10TC $^{2}$ & 78.82 & 12.95 & 5.14 & 0.01 & 1.96 & 0.2 & $<0.01$ & 0.18 & $<0.0003$ & 0.0012 & 0.0007 & $<0.002$ & 0.71 \\
\hline
\end{tabular}

Note: All other elements (Zr, B, Hf, V, W, Ce, Co, Cu, La, Mn, Ni) measured at or below $<0.01$

${ }^{1}$ Vacuum induction melt (VIM) ingot.

${ }^{2}$ Arc-melt and drop cast ingot.

\section{MECHANICAL PERFORMANCE EVALUATION}

\subsection{ENGINEERING MECHANICAL PROPERTIES}

\subsubsection{Properties of the As-received Alloys}

Figure 3 shows the primary specimen geometry (SS-J type) used for mechanical test assessments; the mechanical test results discussed in this section were obtained using this geometry. The detailed description of the mechanical test conditions (grips geometry, tensile frame, DIC setup) are given in our previous reports $[12,13]$. The testing was conducted at room temperature. The nominal strain rate was $10^{-}$ ${ }^{3} \mathrm{~s}^{-1}$; due to strain localization in the weldment area, local strain values might vary. In several cases, data for the SS-Mini specimen type [12] were used because welded SS-J specimens were not available at the time of reporting. 


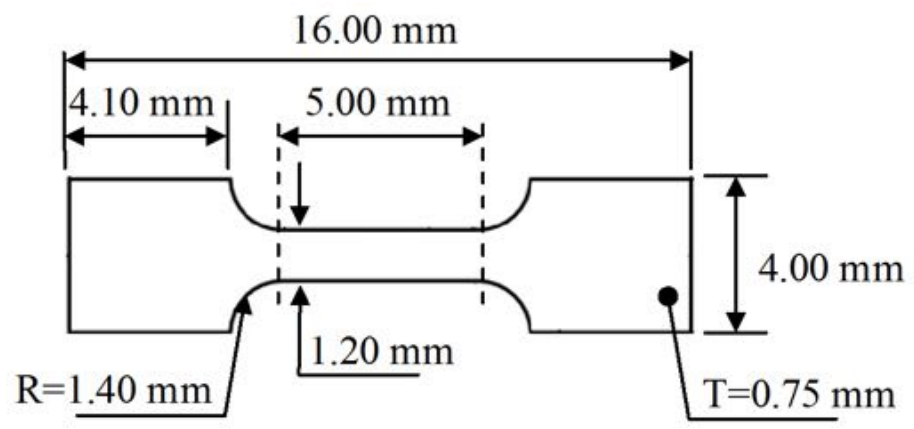

Figure 3. Simplified schematic of the tensile specimen geometry used for mechanical testing. " $T$ " designates the thickness of the specimen.

Figure 4 and Figure 5 show a set of typical tensile curves for each material to illustrate the reproducibility degree and scattering of the results using the SS-J type specimen geometry. The reference alloy data (alloy C35M) are given in both figures. Based on these results, alloying did not lead to any significant changes in the material tensile behavior. The curves kept their general shape and character with a specific Luders-like feature at small strain levels $(\sim 0.01-0.02)$, moderate deformation hardening, and a long descending "tail" corresponding to the neck formation and evolution.
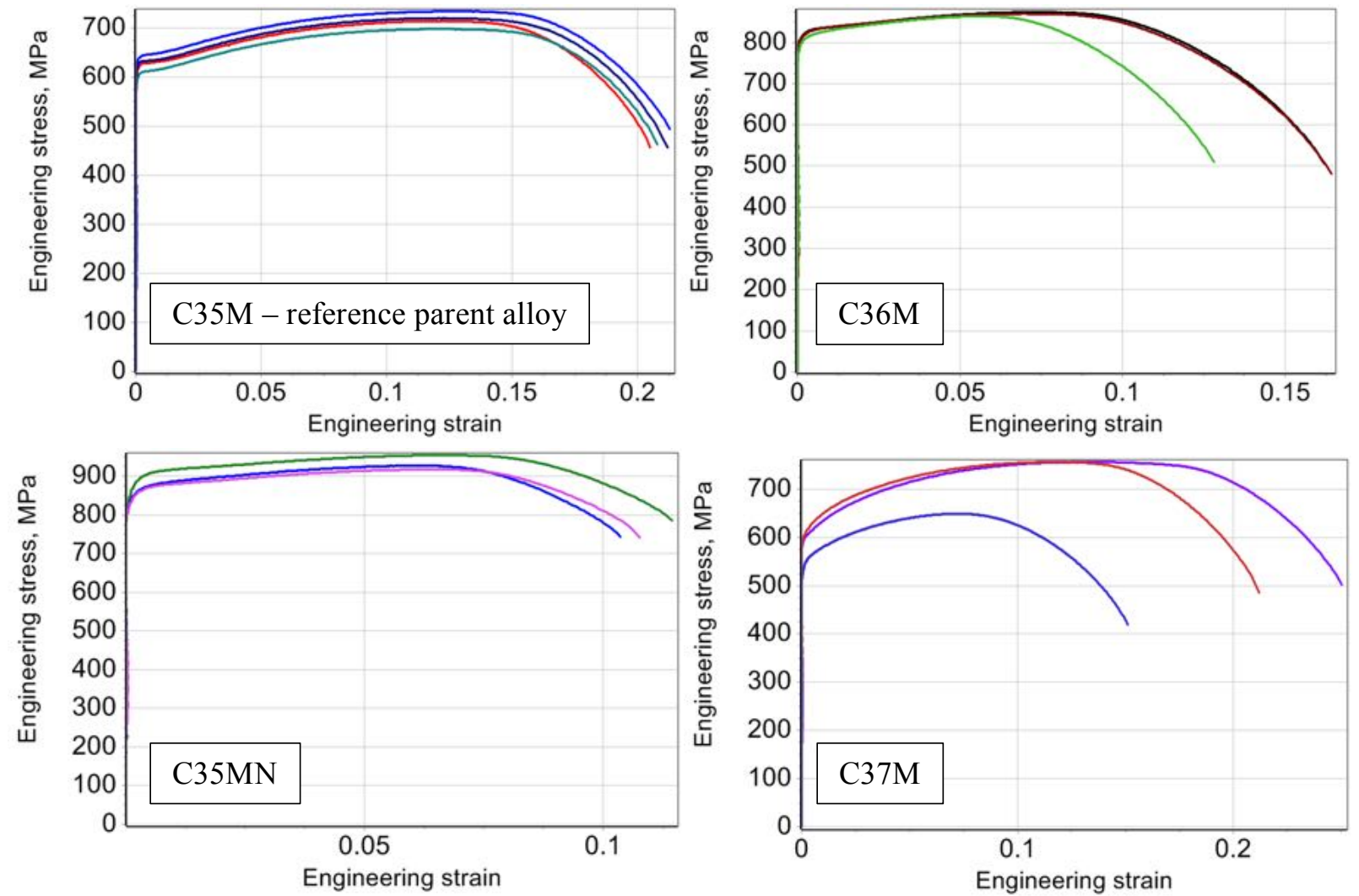

Figure 4. Engineering tensile curves in "engineering stress, MPa-engineering plastic strain" coordinates. Asreceived specimens, ME-branch, SS-J specimen geometry.

In general, data scattering and the difference between the nominally-identical specimens were insignificant. For example, yield stress varied within $10 \%$, and the largest scattering was observed for 
total elongation values. Several specimens demonstrated a strong deviation from the average behavior. It is believed these derivations were caused by defects in the produced plates and local variations in the material composition during small laboratory heat production. In such cases, if obvious defects were observed (see Section 3.2.4), such specimens were removed from the statistics and additional testing was conducted using the specimen reserve pool. Variations in the Al content and the $\mathrm{Nb}$ addition (Figure 4) or the addition of $\mathrm{TiC}$ (Figure 5) did not change the general shape and behavior of the engineering tensile curves with respect to the base reference alloy.
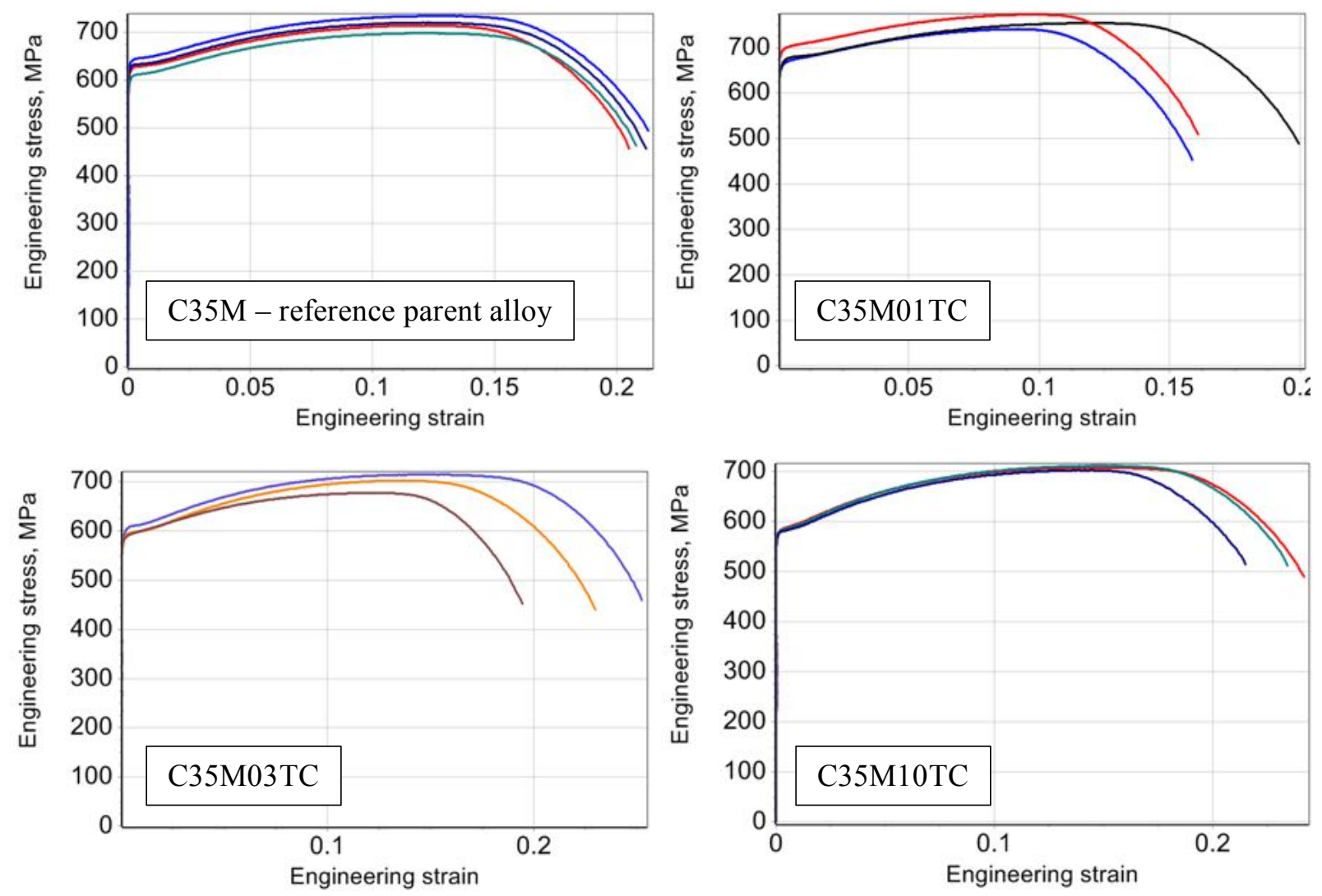

Figure 5. Engineering tensile curves in "engineering stress, MPa - engineering plastic strain" coordinates. Asreceived specimens, TiC-branch, SS-J specimen geometry.

To analyze the alloying role in more detail, a brief summary is given in Figure 6 showing a representative tensile curve per alloy. The average mechanical properties of the as-received alloys are given in Table 2; the table shows the average values after testing at least three identical specimens. One standard deviation value is given in the table to illustrate the result scattering and uncertainty. Regarding standard deviation parameter, it is worth to note that the mechanical test result distribution has a different shape, not purely Gaussian. Thus, the standard deviation value may serve as a qualitative scattering parameter, not quantitative. This aspect may be important if the specimens belong to several groups with distinct behavior, for instance, "brittle" vs. "ductile," as will be discussed below. If two groups exist, standard deviation should not be used. The data scattering will be addressed and discussed in detail in the future reports, when complete structure and mechanical test results, including these for irradiated specimens, are available.

The mechanical test results, Table 2, indicate that niobium additions led to hardening and a ductility decrease compared with the reference material $(\mathrm{C} 35 \mathrm{M}$ vs. $\mathrm{C} 35 \mathrm{MN})$. Al addition played a non-trivial role: $+1 \mathrm{wt} \% \mathrm{Al}$ provided extra hardening, whereas material with $+2 \mathrm{wt} \% \mathrm{Al}(\mathrm{C} 37 \mathrm{M})$ had strength and 
ductility close to those of the reference alloy. Such an effect could be the result of alloying additions or of the differences in plate production mentioned in the previous paragraph.

Addition of $0.1 \mathrm{wt} \% \mathrm{TiC}$ provided extra strength with some decrease in ductility, whereas a further increase in the TiC content $(0.3$ and $1 \mathrm{wt} \%$ in C35M03TC and C35M10TC, respectively) led to a decrease in strength compared with the reference alloy (Figure 6).

In general, no alloying led to a significant degradation in strength or decrease in material ductility. With regard to mechanical performance, before welding, all modified alloys had strength and ductility levels comparable to or superior to those of the parent alloy.
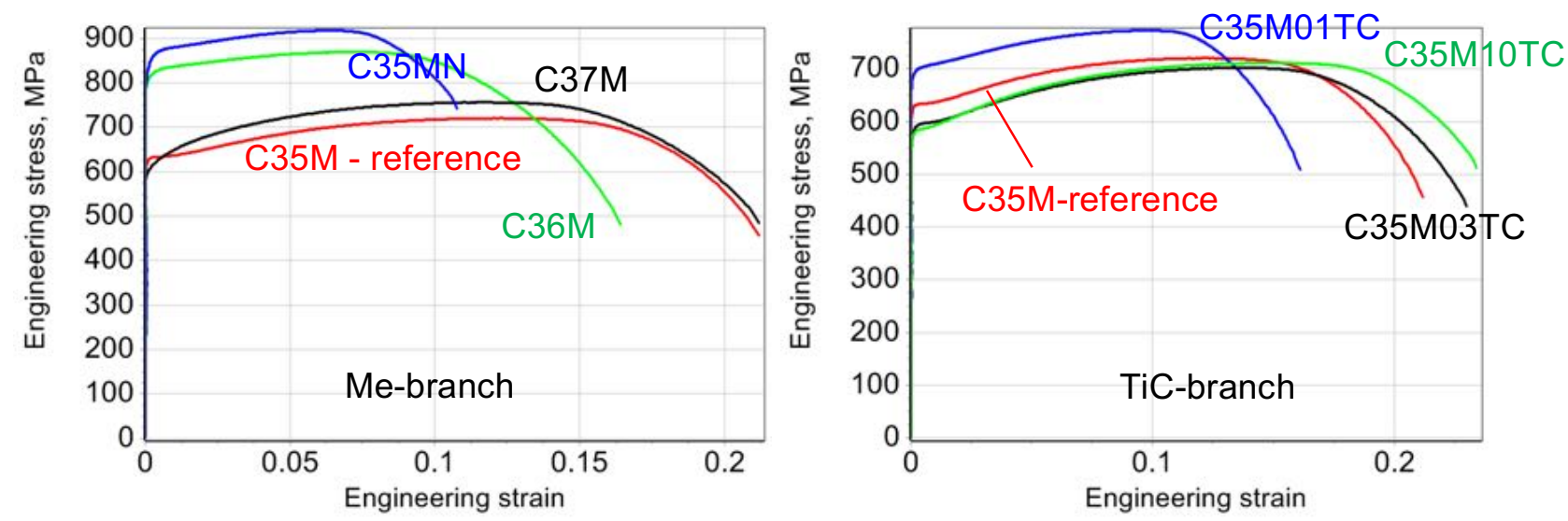

Figure 6. Comparison of the tensile behavior of the investigated alloys: left, ME-branch; right, TiC branch.

One representative tensile curve is given for each material.

Table 2. Mechanical properties of the modified alloys in as-received condition

\begin{tabular}{ccccc}
\hline Alloy & $\begin{array}{c}\text { Yield stress } \\
\text { (MPa) }\end{array}$ & $\begin{array}{c}\text { Ultimate } \\
\text { stress } \\
(\mathbf{M P a})\end{array}$ & $\begin{array}{c}\text { Uniform } \\
\text { elongation } \\
\mathbf{( \% )}\end{array}$ & $\begin{array}{c}\text { Total elongation } \\
\mathbf{( \% )}\end{array}$ \\
\hline \multirow{5}{c}{ Reference } \\
C35M & $627.4 \pm 13.8$ & $\begin{array}{c}717.2 \pm 15 \\
\text { ME branch }\end{array}$ & $12.5 \pm 0.3$ & $20.9 \pm 0.4$ \\
& & & \\
C36M & $814.7 \pm 11.7$ & $869.1 \pm 9.3$ & $6.8 \pm 1.2$ & $15.1 \pm 2.5$ \\
C37M & $587.2 \pm 33$ & $720.9 \pm 61.9$ & $10.8 \pm 3.4$ & $20.4 \pm 5.0$ \\
C35MN & $863.1 \pm 17.5$ & $933.6 \pm 19$ & $6.3 \pm 0.5$ & $10.9 \pm 0.5$ \\
& & TiC branch & \\
C35MT01 & $674.4 \pm 14.6$ & $755.2 \pm 13.4$ & $10.7 \pm 1.3$ & $17.8 \pm 2.1$ \\
C35MT03 & $595.3 \pm 8.1$ & $701.8 \pm 17$ & $13.2 \pm 1.0$ & $22.5 \pm 2.4$ \\
C35MT10 & $581.6 \pm 1.9$ & $707.5 \pm 4.6$ & $14.6 \pm 0.1$ & $23.0 \pm 1.4$ \\
\hline
\end{tabular}




\subsubsection{Mechanical Properties after Welding}

At least three nominally identical specimens were tested per condition. Table 3 shows the mechanical properties of the alloys after welding; one standard deviation value is also shown to estimate the uncertainty in the strength and ductility values. All tested welds were from a pulsed laser-welding machine using autogenous, bead-on-plate welding along the traverse rolling direction. Tensile specimens were extracted from the welds with the gauge length aligned to the rolling direction of the welded plate resulting in the weld bead being aligned in the centered of the gauge length. The full welding procedure including the extraction map is described in detail in a previous report [13]; initial microstructural observations, including electron backscatter diffraction (EBSD) data, have also been previously reported [11]. Note that post-welding data are not available for the C36M alloy. It was assumed that its behavior after welding would reside within the same range as that of the C35M and C37M alloys. Because of limited volume in the irradiation capsules, it is not currently being investigated in the welded state as part of the irradiation program [14].

As follows from Table 3, all alloys experienced yield stress reductions after welding. This was most likely due to recrystallization (the materials were in partly recrystallized condition) and grain growth in the fusion zone and surrounding regions during welding. Note that the yield stress reduction, although significant, was not consistent with the manner of welding-induced softening. This was the conclusion because all yield stress values (presented in Table 3) were above $500 \mathrm{MPa}$ for all investigated alloys except the parent material, C35M. The degree of softening in $\mathrm{C} 35 \mathrm{M}$ could be the result of the different specimen geometry (SS-J versus SS-Mini) compared with the other alloys, for which only the SS-J specimen geometry was used to populate Table 3. The lowest decrease in yield stress values was observed for the C35MN alloy across both alloying branches.

Table 3. Mechanical properties of the modified alloys after welding*

\begin{tabular}{|c|c|c|c|c|c|c|c|}
\hline Alloy & Conditions & $\begin{array}{c}\text { Yield stress, } \\
\sigma_{02}(\mathrm{MPa})\end{array}$ & $\begin{array}{l}\text { Ultimate } \\
\text { stress } \\
\text { (MPa) }\end{array}$ & $\begin{array}{c}\text { Uniform } \\
\text { elongation } \\
(\%)\end{array}$ & $\begin{array}{c}\text { Total } \\
\text { elongation } \\
(\%)\end{array}$ & $\begin{array}{c}\text { Softening } \\
\text { Degree, } \\
\Delta \sigma_{02} / \sigma_{02}-\mathrm{AR} \\
(\%) \\
\end{array}$ & $\begin{array}{l}\text { Sudden } \\
\text { fracture } \\
\text { events }\end{array}$ \\
\hline \multicolumn{8}{|c|}{ Reference } \\
\hline \multirow{2}{*}{$\mathrm{C} 35 \mathrm{M}$} & As-received & $627.4 \pm 13.8$ & $717.2 \pm 15$ & $12.5 \pm 0.3$ & $20.9 \pm 0.4$ & \multirow{2}{*}{$26 \%$} & No \\
\hline & Welded** & $464.3 \pm 18.5$ & $563.8 \pm 23.2$ & $6.8 \pm 0.9$ & $17.5 \pm 4.2$ & & No \\
\hline \multicolumn{8}{|c|}{ ME-branch* } \\
\hline \multirow{2}{*}{$\mathrm{C} 37 \mathrm{M}$} & As-received & $587.2 \pm 33$ & $720.9 \pm 61.9$ & $10.8 \pm 3.4$ & $20.4 \pm 5.0$ & \multirow{2}{*}{$12 \%$} & No \\
\hline & Welded & $\mathbf{5 1 4 . 0} \pm 15.6$ & $629.0 \pm 10.5$ & $\mathbf{4 . 5} \pm 0.1$ & $\mathbf{4 . 5} \pm 0.1$ & & Yes $(>50 \%)$ \\
\hline \multirow{2}{*}{$\mathrm{C} 35 \mathrm{MN}$} & As-received & $863.1 \pm 17.5$ & $933.6 \pm 19$ & $6.3 \pm 0.5$ & $10.9 \pm 0.5$ & \multirow{2}{*}{$34 \%$} & No \\
\hline & Welded & $\mathbf{5 6 9 . 0} \pm 4.1$ & $\mathbf{6 3 1 . 3} \pm 18.4$ & $\mathbf{2 . 3} \pm 1.4$ & $\mathbf{5 . 4} \pm 5.2$ & & Yes $(\sim 50 \%)$ \\
\hline \multicolumn{8}{|c|}{ TiC-branch } \\
\hline \multirow{2}{*}{ C35M01TC } & As-received & $674.4 \pm 14.6$ & $755.2 \pm 13.4$ & $10.7 \pm 1.3$ & $17.8 \pm 2.1$ & \multirow{2}{*}{$19 \%$} & No \\
\hline & Welded & $\mathbf{5 4 5 . 8} \pm 6.8$ & $623.8 \pm 7.5$ & $\mathbf{4 . 9} \pm 0.7$ & $12.6 \pm 2.6$ & & No \\
\hline \multirow[b]{2}{*}{ C35M03TC } & As-received & $595.3 \pm 8.1$ & $701.8 \pm 17$ & $13.2 \pm 1.0$ & $22.5 \pm 2.4$ & \multirow[b]{2}{*}{$11 \%$} & No \\
\hline & Welded & $\mathbf{5 2 8 . 9} \pm 19.1$ & $\mathbf{6 5 0 . 9} \pm 18.9$ & $\mathbf{5 . 6} \pm 1.6$ & $9.1 \pm 4.7$ & & $\begin{array}{c}\text { Yes (single } \\
\text { spec.) }\end{array}$ \\
\hline \multirow{2}{*}{ C35M10TC } & As-received & $581.6 \pm 1.9$ & $707.5 \pm 4.6$ & $14.6 \pm 0.1$ & $23.0 \pm 1.4$ & \multirow{2}{*}{$11 \%$} & - \\
\hline & Welded & $\mathbf{5 1 8 . 8} \pm 24.5$ & $683.4 \pm 38.4$ & $\mathbf{6 . 8} \pm 0.5$ & $12.0 \pm 0.6$ & & No \\
\hline
\end{tabular}


To estimate the welding role in the yield stress, it seems reasonable to define a softening degree parameter: ratio of the yield stress change $\left(\Delta \sigma_{02}=\sigma_{02-A R}-\sigma_{02-\mathrm{W}}\right)$ to the initial yield stress $\left(\sigma_{02-\mathrm{AR}}\right)$. Based on this parameter (Table 3 ), the softening degree varied and was the highest for alloys that experienced limited recrystallization during initial processing prior to welding (C37M and C35M10TC).

The ultimate stress, showing the maximum carrying capacity and illustrating the deformation hardening behavior, is also of interest. All welded alloys demonstrated an ultimate stress level of $600 \mathrm{MPa}$ or greater. It is interesting that ultimate stress increased for the $\mathrm{TiC}$ branch alloys with increasing $\mathrm{TiC}$ additions from 0.1 to $1.0 \mathrm{wt} \%$. This effect could be directly related to the role of the TiC dispersions in the matrix.

Since the welded specimens are complex objects with multiple areas (e.g., as-received material, HAZs, fusion zone), ductility values obtained from engineering tensile curves have limited value. DIC data are discussed in Section 3.3 to estimate the hardening behavior of the investigated welded alloys in detail and provide a more robust assessment of the alloys after welding. Nevertheless, the uniform and total elongation values defined from the engineering tensile curves are acceptable as qualitative indications of the material ductility and general deformation behavior of the materials.

As follows from the data in Table 3, welded ME-branch specimens, in general, demonstrated smaller average ductility than the TiC-branch specimens. In many cases, the tensile curves for the welded specimens were smooth (Figure 7 and Figure 8) with pronounced deformation hardening and necking after yielding.

However, unexpected (or "sudden") fracture events were observed for some welded ME-branch specimens (Figure 7). The sudden fractures usually happened in the small strain area after yielding, below $\sim 5 \%$ ( 0.05) plastic strain. The specimen fractured without the formation of a visible neck; the local area reduction was also very small or nonexistent. The appearance of such sudden fracture events suggests that some investigated materials are sensitive to internal defects or flaws, such as small cracks or internal porosity. In the future, fracture toughness tests may be suitable for estimating the true embrittlement degree of the modified alloys after welding but fell out of the scope of the current program.
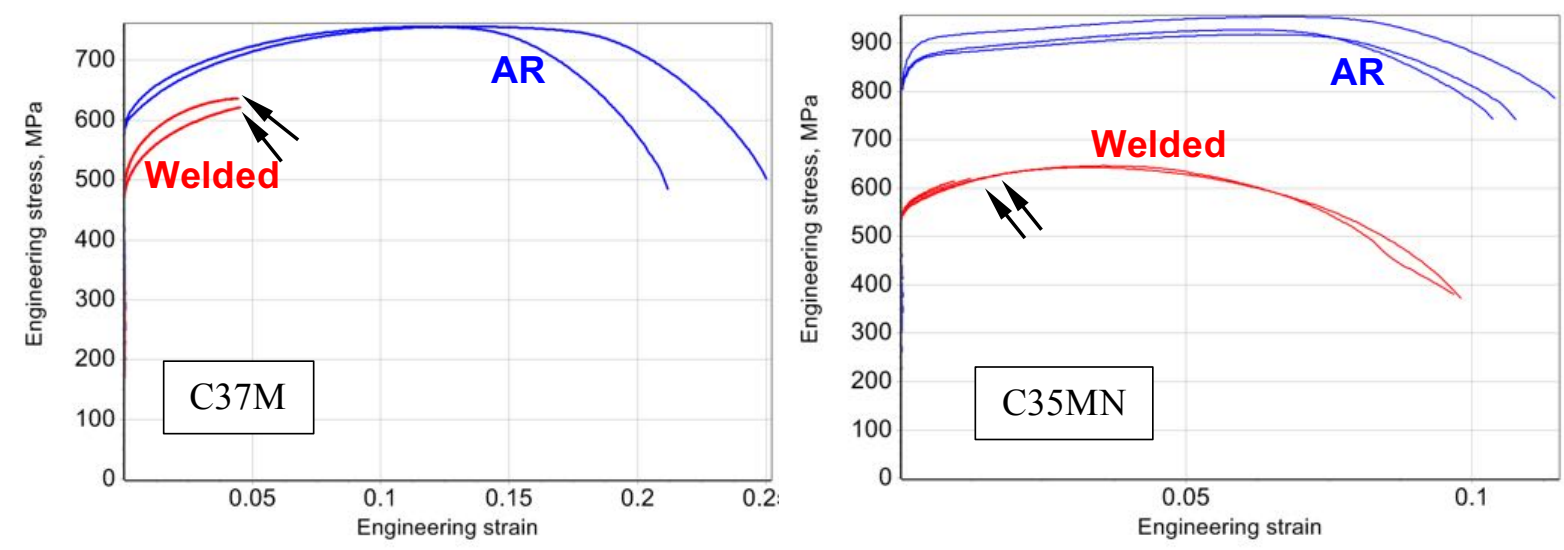

Figure 7. Engineering tensile diagrams in "plastic strain-engineering stress" coordinates for the as-received (“AR", blue) and welded (red) specimens (ME-branch alloys). Sudden fracture events are marked with arrows.

Such sudden fractures were observed for (roughly) 1/3 of all tested ME-branch welded specimens $(\mathrm{C} 37 \mathrm{M}, \mathrm{C} 35 \mathrm{MN})$. However, this kind of fracture behavior was much less frequent for the TiC-branch 
alloys; only one such event was observed for the SS-J specimen geometry (Figure 8). It may be speculated that TiC-branch alloys are less prone to welding-induced embrittlement than are ME-branch alloys. According to Dupont et al. [9], the sensitivity of FeCrAl-alloys to hydrogen-induced embrittlement may be mitigated by $(\mathrm{Fe}, \mathrm{Cr})_{\mathrm{x}} \mathrm{C}_{\mathrm{y}}$ and $(\mathrm{Fe}, \mathrm{Al})_{3} \mathrm{C}$ type carbides. Carbide particles may work as effective hydrogen traps, reducing the degree of hydrogen embrittlement. This could be a contributing reason for their decreased propensity to these sudden fracture events. Another plausible reason is the processing routes for the two different alloying branches. Based on Table 1 and previous reports [11], the ME-branch specimens were vacuum induction melt (VIM) cast ingots before additional processing whereas the TiC-branch specimens were processed by arc-melting. This variance in ingot production could be introducing additional defects in the VIM-processed materials that lead to sudden fracture events. Further work, such as producing the ME-branch alloys using arc-melting, could provide insight into the controlling factor. However, because of the large amount of effort that would be needed to accomplish this work, it falls out of the scope of the current program.
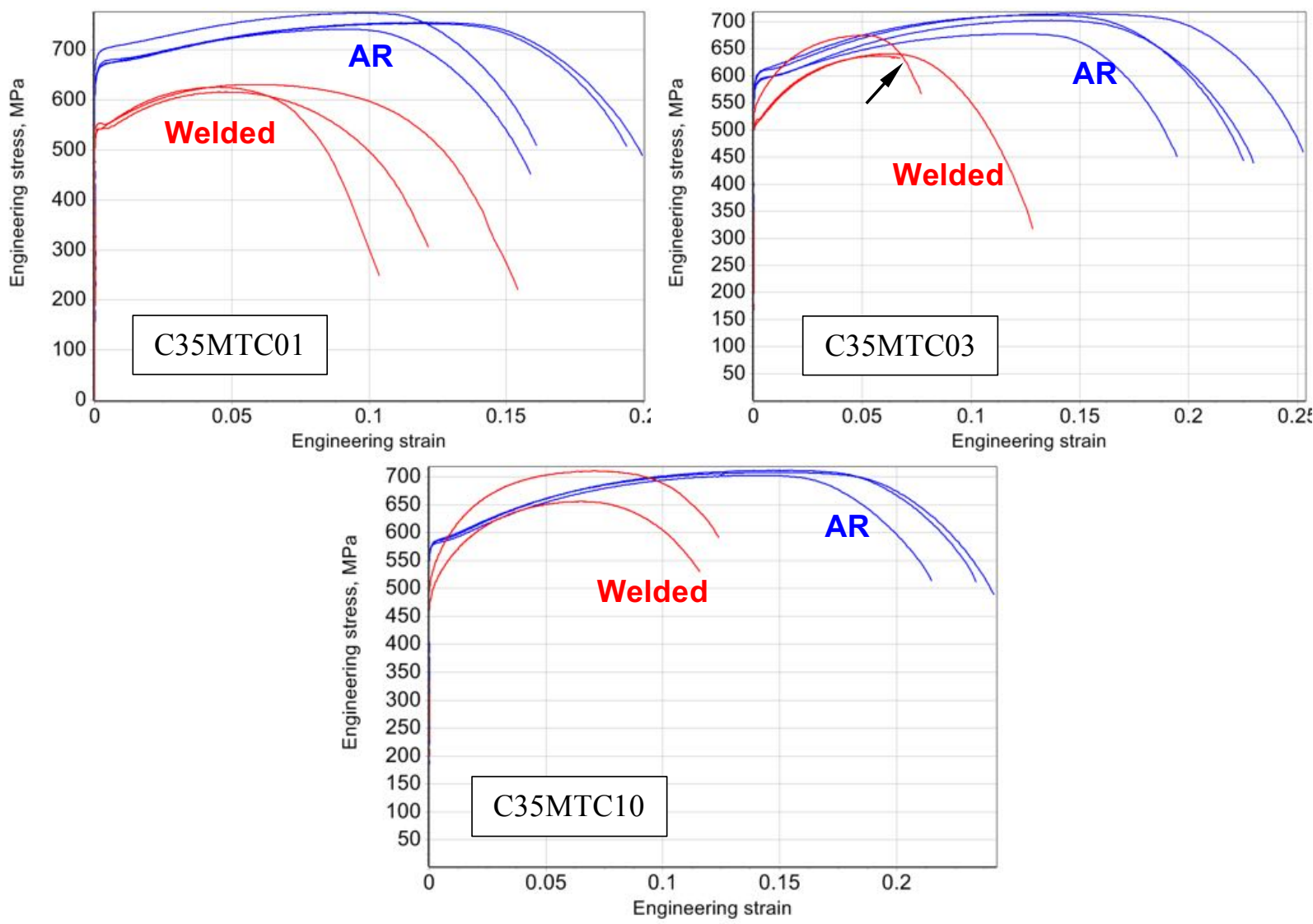

Figure 8. Engineering tensile diagrams in "plastic strain-engineering stress" coordinates for the as-received (blue) and welded (red) specimens (TiC-branch alloys). A sudden fracture event (only one was observed) is pointed out with an arrow.

\subsection{FRACTOGRAPHY}

Scanning electron microscopy (SEM) analysis of the fracture surface (fractography) was conducted after the tensile tests. Fractography can provide further insight into the deformation behavior, including the degree of localized necking and the fracture mode of the specimen-i.e., brittle fracture, ductile fracture, 
or mixed mode (ductile + brittle) fracture. To prevent fracture surface damage or contamination, the designated tested specimens were stored in gel boxes. At least two specimens (one SS-J and one SS-Mini) were analyzed per condition. A FEI Versa dual-beam focused ion beam/SEM (FIB/SEM) with a field emission gun was used in both secondary electron (SE) and backscattered electron (BSE) modes to observe the fracture surface topography.

\subsubsection{Analysis of the Fracture Surface}

Figure 9 shows the typical behavior of the parent C35M alloy, which demonstrated a high reduction of area (RA) and a fully ductile fracture surface based on the dimple and cone topography (Figure 9, right). No cleavage spots were observed among the analyzed C35M specimens. Modified alloys (Figure 10 and Figure 11) also had ductile fractures before welding. Most unwelded specimens had ductile fracture surfaces with pronounced necking, resulting in high RA values. C36M demonstrated a specific multilayer structure caused most likely by the processing and alignment of critical defects, such as stringers aligned with the rolling direction during final processing.
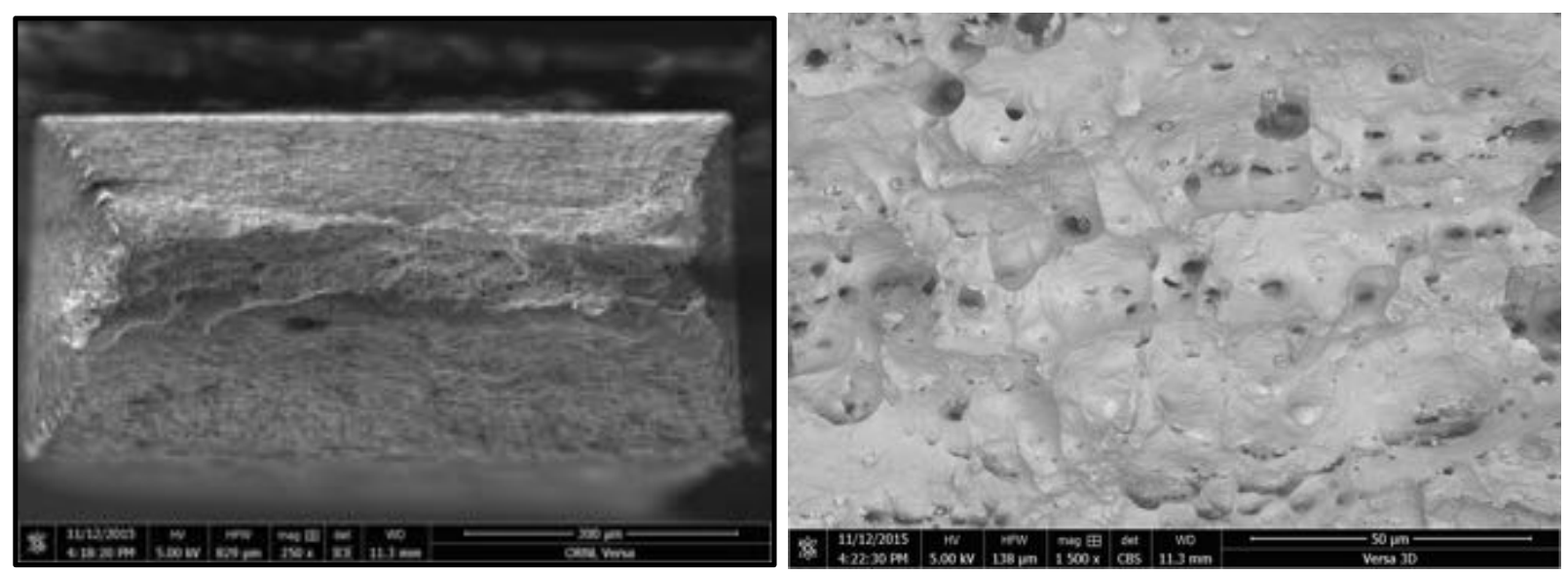

Figure 9. Parent alloy: (left) SE imaging mode and (right) BSE imaging mode at a higher magnification of the fracture surface of the $\mathbf{C 3 5 M}$ alloy specimen. Relatively high area reduction can be observed; the whole final fracture surface has a dimple and cone appearance, indicative of a ductile fracture.

Welding led to pronounced changes in the neck shape and fracture surface appearance (Figure 10 and Figure 11, right). The neck had a specific "diamond-like" shape, not a rectangle as before welding. For example, see Figure 12. The fracture mechanisms changed from fully ductile to mixed (ductile + cleavage) or fully brittle fracture behavior. Multiple signs of delayering were observed. 
As-received

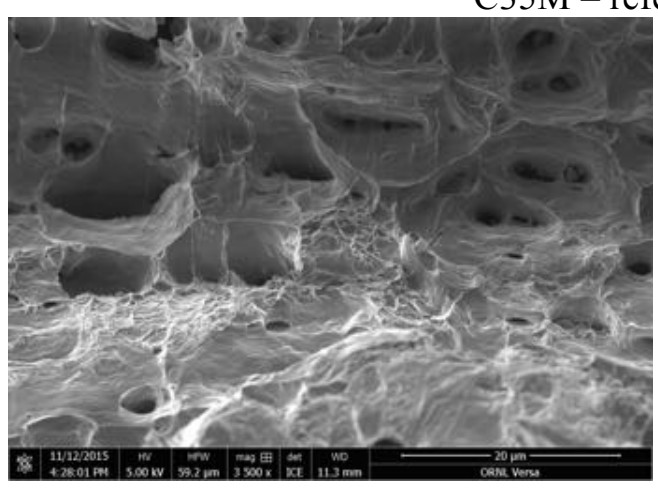

$\mathrm{n} / \mathrm{a}$
$\mathrm{C} 35 \mathrm{MN}$
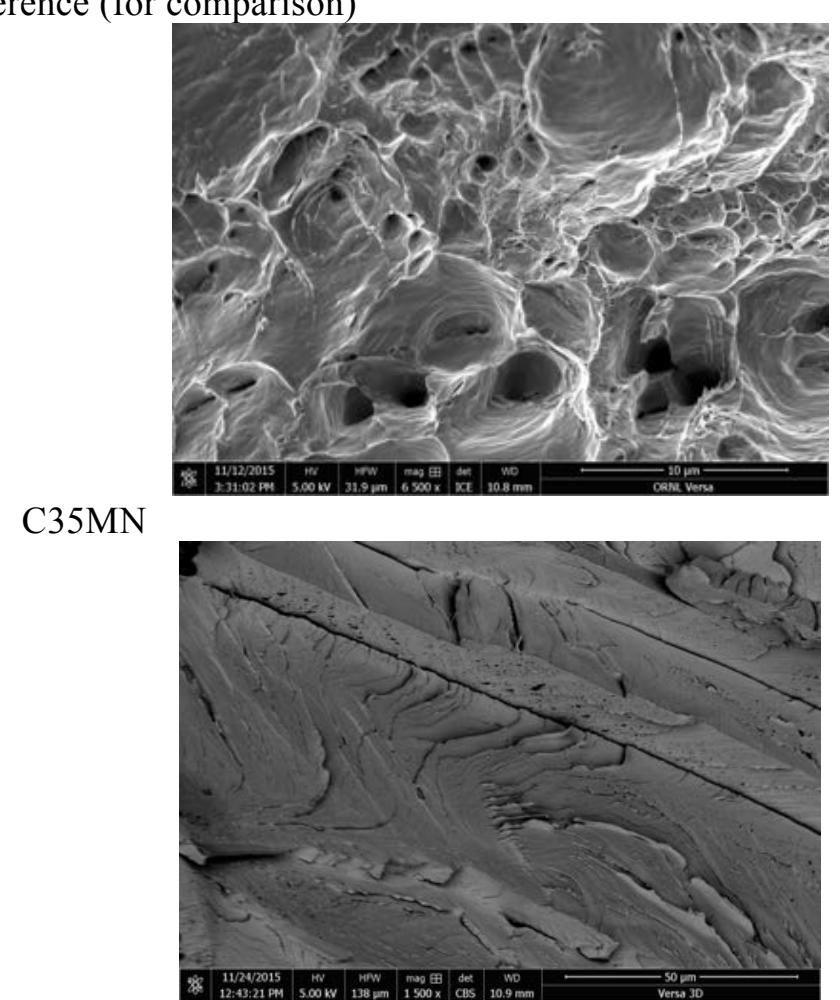

$\mathrm{C} 36 \mathrm{M}$

$\mathrm{C} 36 \mathrm{M}$

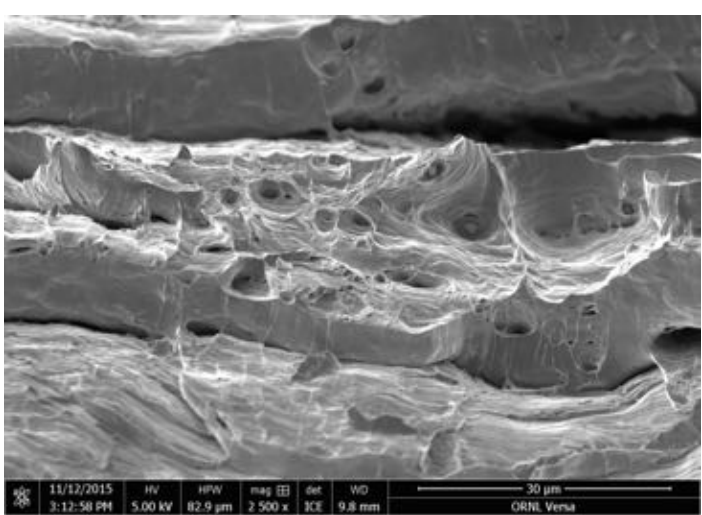

After welding

$\mathrm{n} / \mathrm{a}$

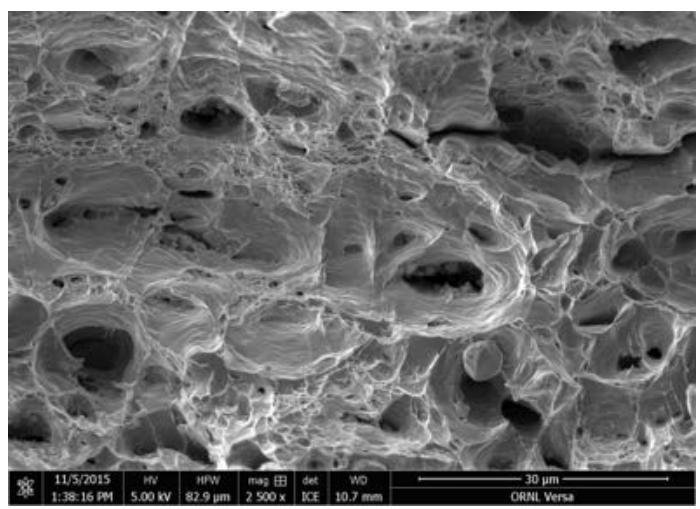

$\mathrm{C} 37 \mathrm{M}$

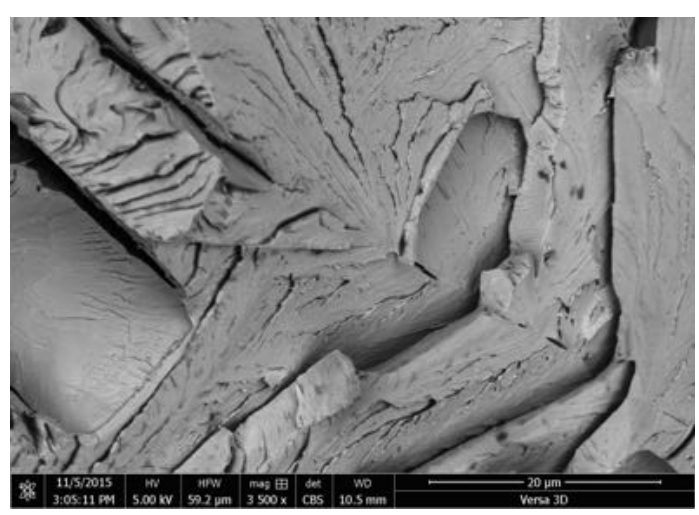

Figure 10. The role of alloying and welding in the fracture mechanism (ME branch). 
As-received

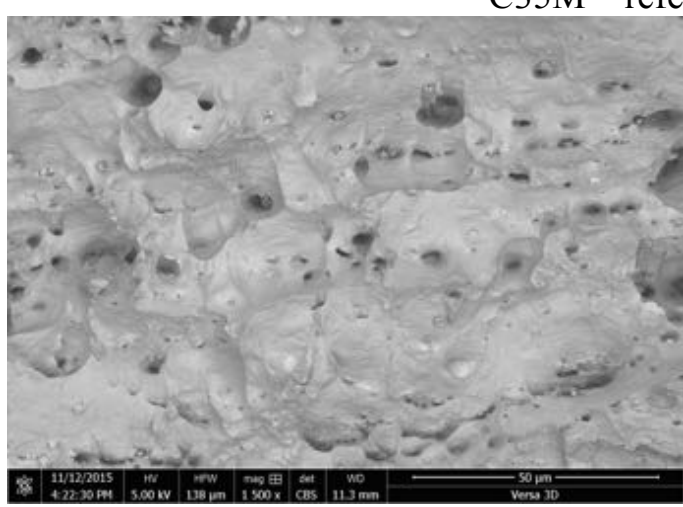

C35M01TC

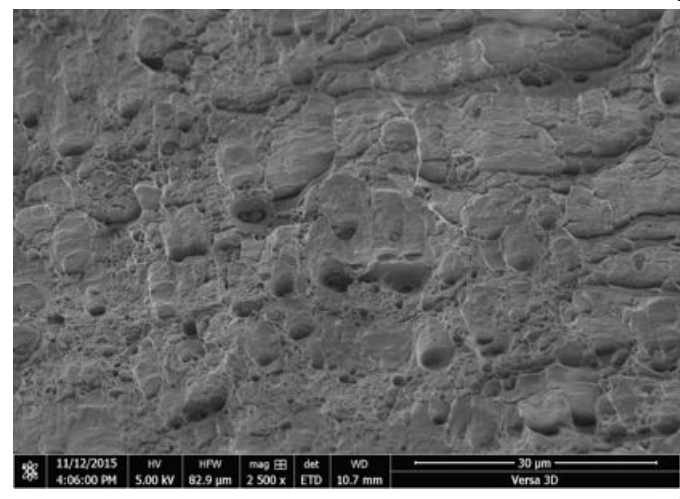

C35M03TC

$\mathrm{n} / \mathrm{a}$

C35M10TC
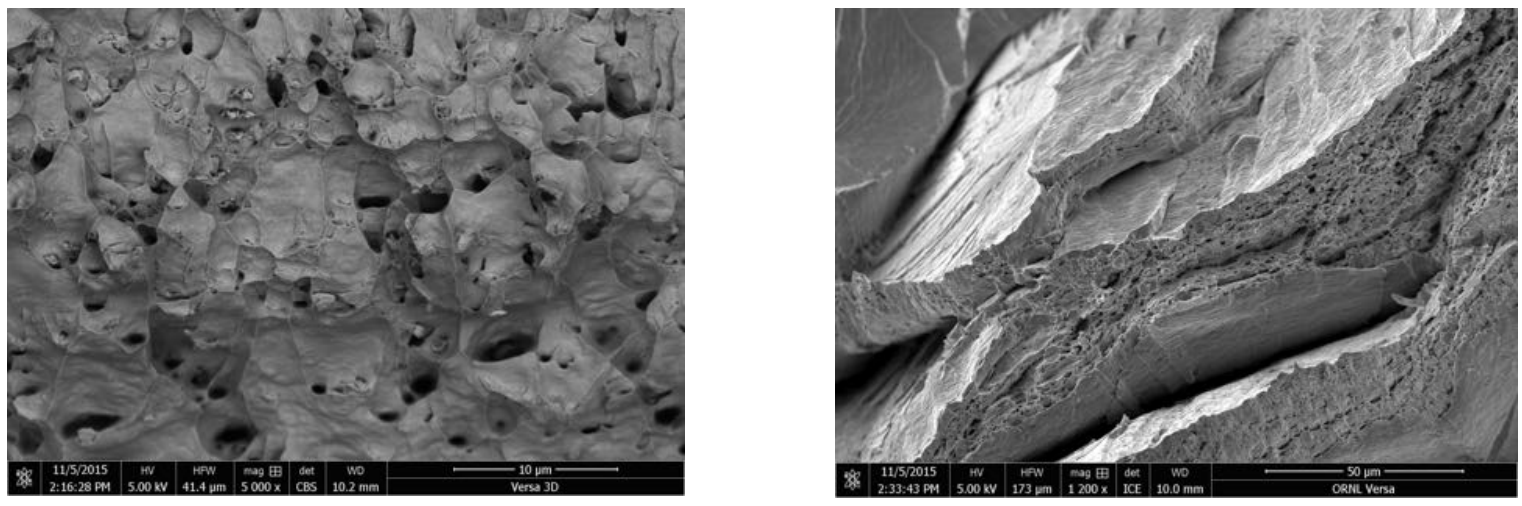

Figure 11. The role of alloying and welding in the fracture mechanism ( $\mathrm{TiC}$ branch). 

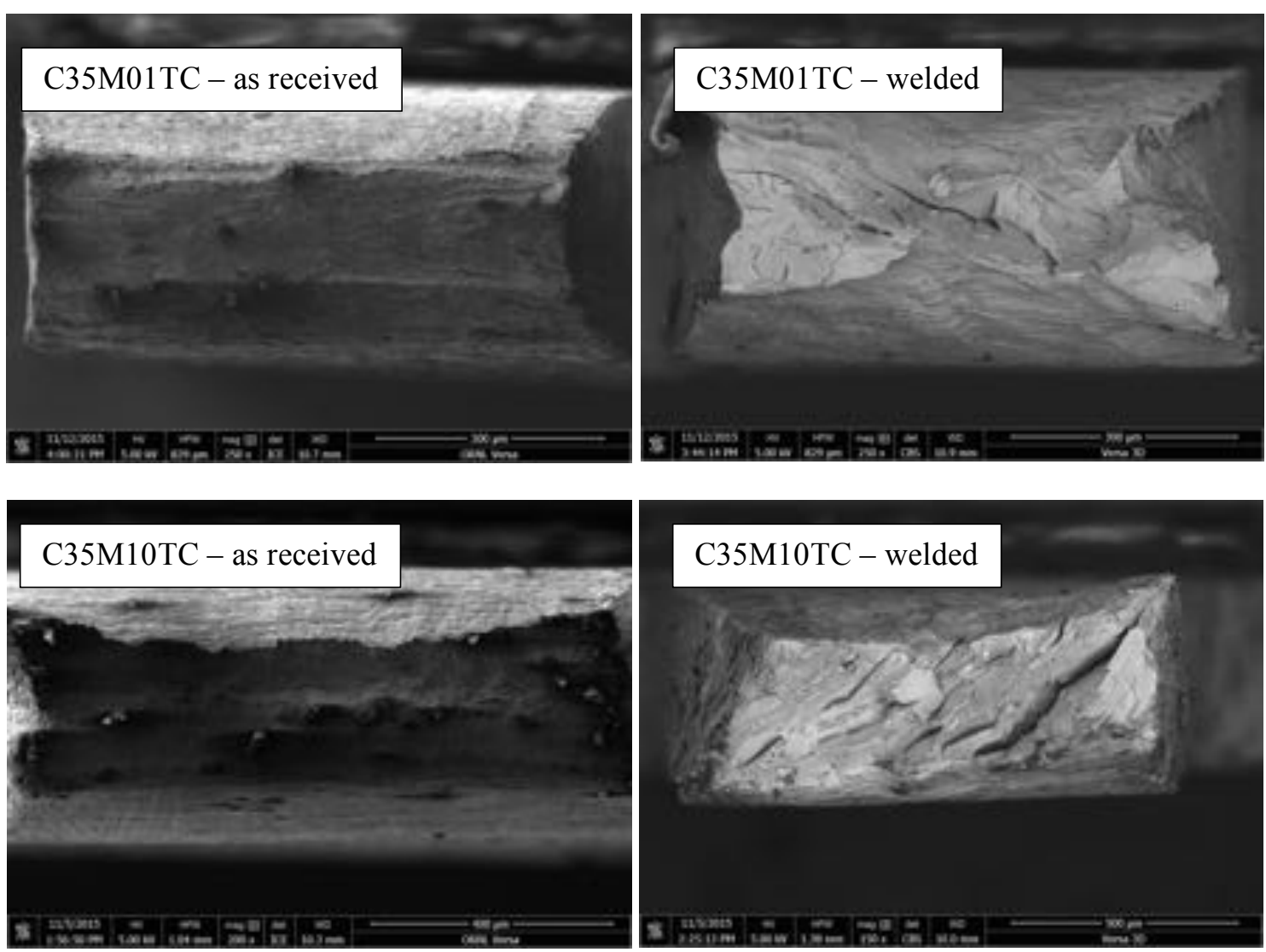

Figure 12. The general appearance of the fracture surface of TiC branch specimens: as-received vs. welded.

The embrittlement degree (the ratio between ductile dimple and cleavage fractions) varied among the studied alloys (Table 4). Modified materials from the ME branch had a cleavage fracture surface, fully brittle and practically without dimples. The TiC-branch alloys, as a rule, had mixed fracture surfaces. The largest ductile fracture fraction ( $50 \%)$ was observed in C35M10TC with $1 \mathrm{wt} \% \mathrm{TiC}$.

Table 4. Summary of the fracture mechanism for the investigated alloys (average data for both SS-JS and SSMinis)

\begin{tabular}{|c|c|c|c|c|c|c|c|}
\hline \multirow{2}{*}{$\begin{array}{l}\text { Alloy/ } \\
\text { conditions }\end{array}$} & \multirow{2}{*}{$\frac{\text { Parent }}{\text { C35M }}$} & \multicolumn{3}{|c|}{ Me-branch } & \multicolumn{3}{|c|}{ TiC-branch } \\
\hline & & C36M & C37M & C35MN & C35M01TC & C35M03TC & C35M10TC \\
\hline As-received & Ductile & $\begin{array}{c}\text { Ductile }+ \text { some } \\
\text { cleavage }(<20 \%)\end{array}$ & Ductile & Ductile & Ductile & $\mathrm{n} / \mathrm{d}$ & Ductile \\
\hline $\begin{array}{l}\text { After } \\
\text { welding }\end{array}$ & Ductile & $\mathrm{n} / \mathrm{d}$ & $\begin{array}{l}\text { Brittle/ } \\
\text { cleavage }\end{array}$ & $\begin{array}{l}\text { Brittle/ } \\
\text { cleavage }\end{array}$ & $\begin{array}{c}\text { Mixed mode } \\
\text { (duct. } \sim 30 \% \text {, } \\
\text { cleavage } \sim 70 \% \text { ) }\end{array}$ & $\begin{array}{l}\text { Brittle, } \\
\text { cleavage }\end{array}$ & $\begin{array}{l}\text { Mixed } \\
\text { (ductility } \\
\sim 50 \% \text {, } \\
\text { cleavage } \\
\sim 50 \% \text { ) }\end{array}$ \\
\hline
\end{tabular}

\subsubsection{Detailed Analysis of Necking (Specimen Cross-section) in the Welded Specimen}

Taking into account the complex fracture behavior discussed above, it was important to analyze the specimen cross-section to reveal internal cracks in the weldment after tensile tests and check for other defects. The cross-sections of the welded objects had been analyzed using optical microscopy and low- 
magnification SEM before tensile testing, and no cracks or other welding-induced defects were observed [13].

Specimen ID HW26 was selected for the cross-section preparation and detailed examination. This alloy (C35M10TC) contains the largest amount of added TiC ( 1 wt \%), providing the opportunity to analyze its role and conditions in detail. Also, this material demonstrated mixed fracture mode with the fracture surface containing both cleavage and ductile dimple areas (Figure 11).

For the HW26 specimen cross-section, low- and moderate-magnification SEM analysis revealed small internal cracks in the vicinity of the fracture surface (Figure 13 and Figure 14). No cracks were observed in the bulk weldment far from the fracture location. The EDM layer can be observed on the upper and bottom edges of the samples, but did not show significant contribution to the cracking behavior. The degree of internal cracking could be the result of internal defects promoting the formation of cracks in highly strained areas. Such defect/crack synergies are consistent with previous discussions of the contributing effect of defects on the fracture properties of the candidate $\mathrm{FeCrAl}$ alloys. Additionally, voids were a common defect type near the fracture location. Void size and density strongly increased near the fracture surface (Figure 15). Void formation is indicative of ductile fracture where a final fracture occurs as a result of void nucleation, growth, and finally coalescence. The appearance of both internal cracking and void formation supports the mixed-mode findings presented in Table 4 for C35M10TC.

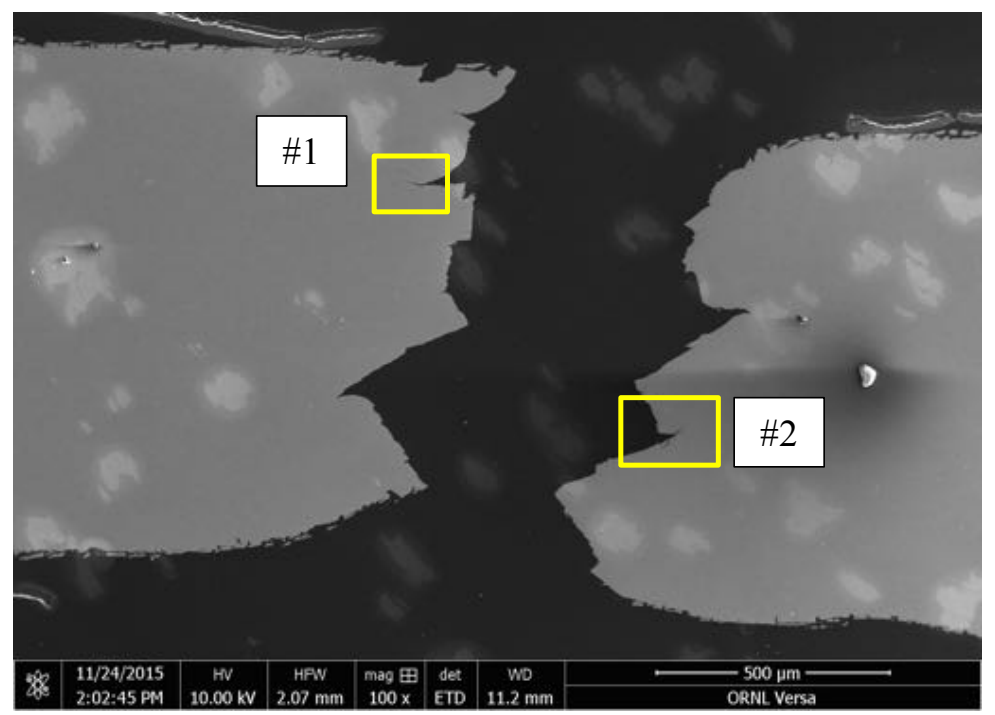

Figure 13. Cross-sectional view of the tensile specimen halves from Specimen ID HW26. A layer induced by electrical discharge machining can be seen on the outer edges. Areas 1 and 2 are shown in greater detail in Figure 14. 

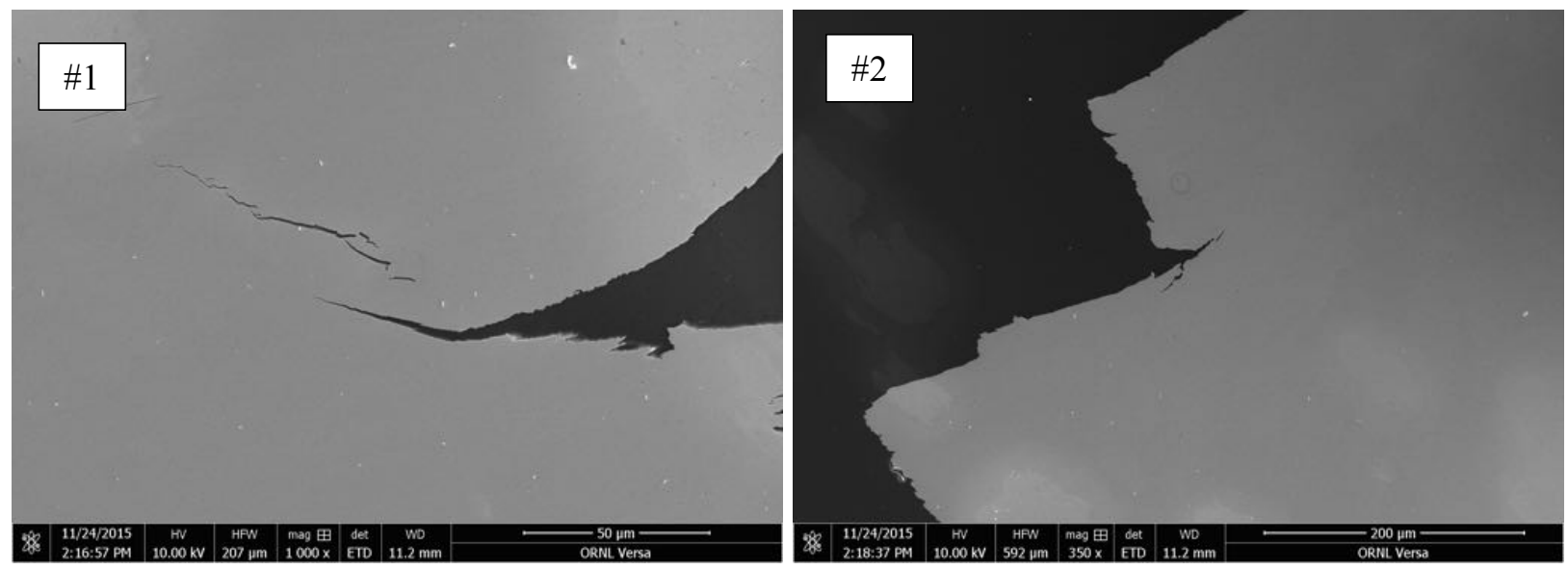

Figure 14. Complex character of cracking and internal cracks in the weldment.
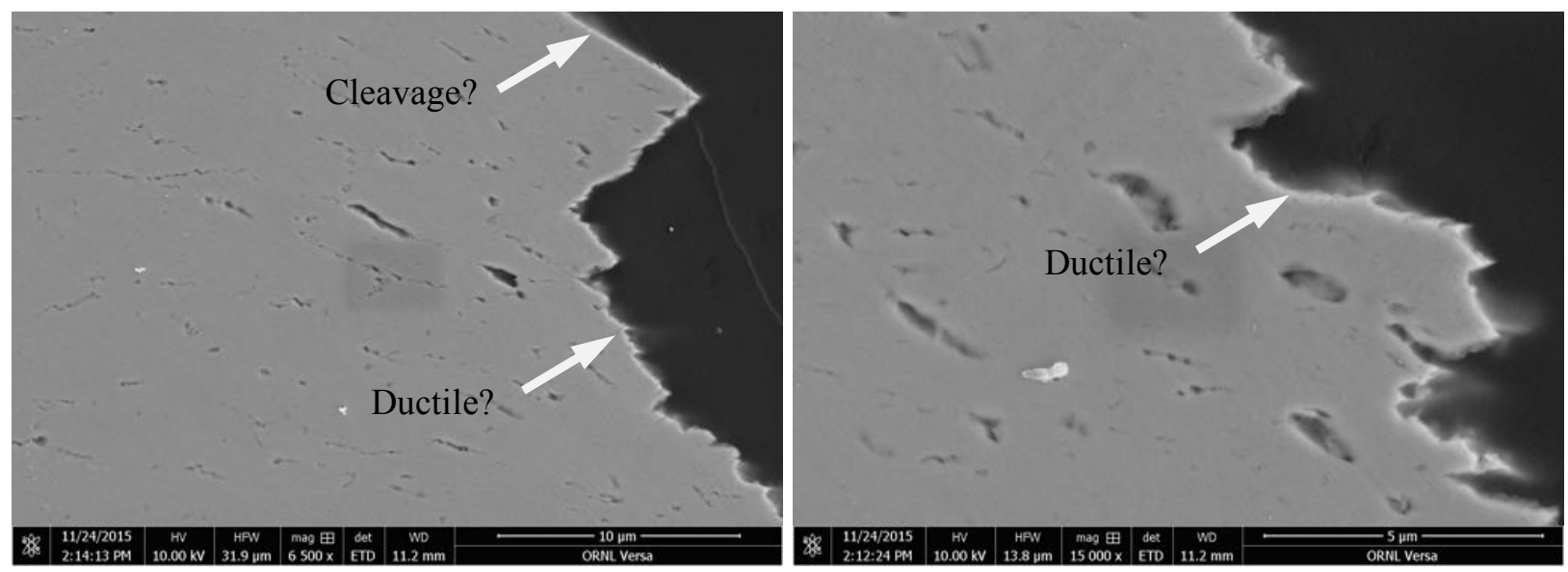

Figure 15. Strain-induced voids and small crack near the fracture point.

\subsubsection{EBSD Scanning of the Near-fracture Region in HW26}

Detailed EBSD analysis was not a major goal at this point of the investigation; however, it was interesting to investigate the strain-induced processes in more detail. Unfortunately, the EBSD scanning rate was low because larger electron beam current values led to epoxy swelling and fracture. Epoxy mounts were used to preserve the cross-section fracture surface and generate mirror-like finishes on the specimen. Thus, only general, coarse-step scans were performed. Future work could see sample preparation without epoxy impregnation to eliminate such hardships in EBSD analysis.

Figure 16 shows the scan location (close to the fracture surface) and the corresponding inverse pole figure (IPF) map. The weldment before deformation had relatively coarse grains of random orientation, as follows from the previous report [11]. During straining, the grains inside the weldment experienced rotation, forming a strong [101] texture. The local misorientation profiles (Figure 17) show in-grain misorientation, with the left point taken as a reference value. These profiles reflect two processes: grain rotation and fragmentation during plastic deformation and strong deformation and rotation near the fracture surface. It appears that the final fracture leads to plastic deformation in a $\sim 40-50 \mu \mathrm{m}$ layer. 


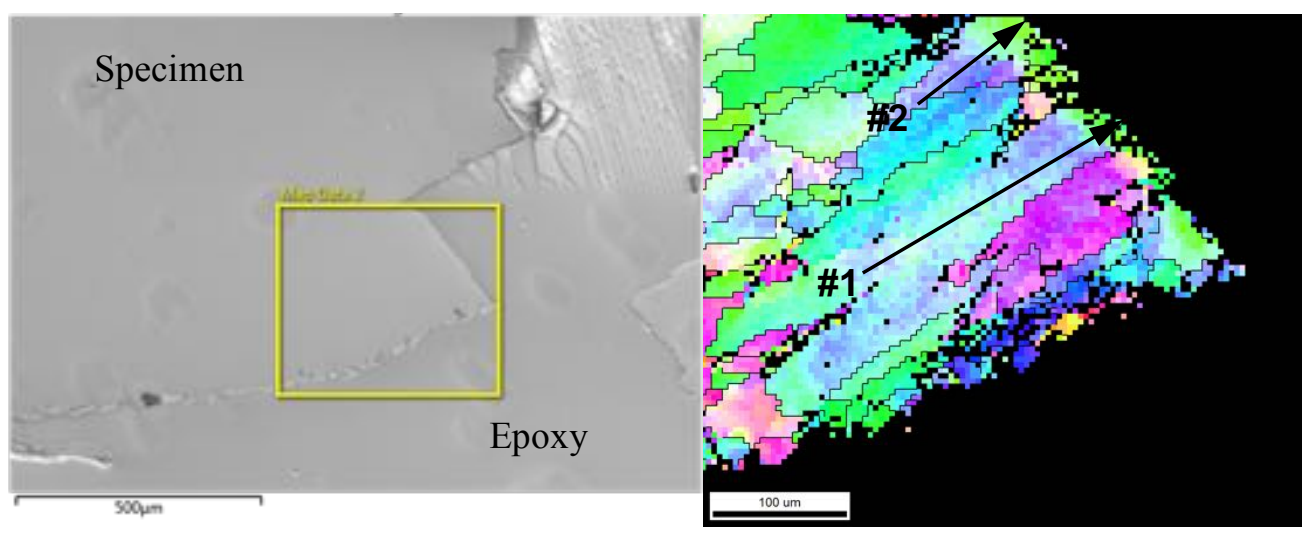

Figure 16. Location of the EBSD scan and corresponding IPF map colored in the tensile direction. Areas 1 and 2 are misorientation profile locations (see Figure 17).
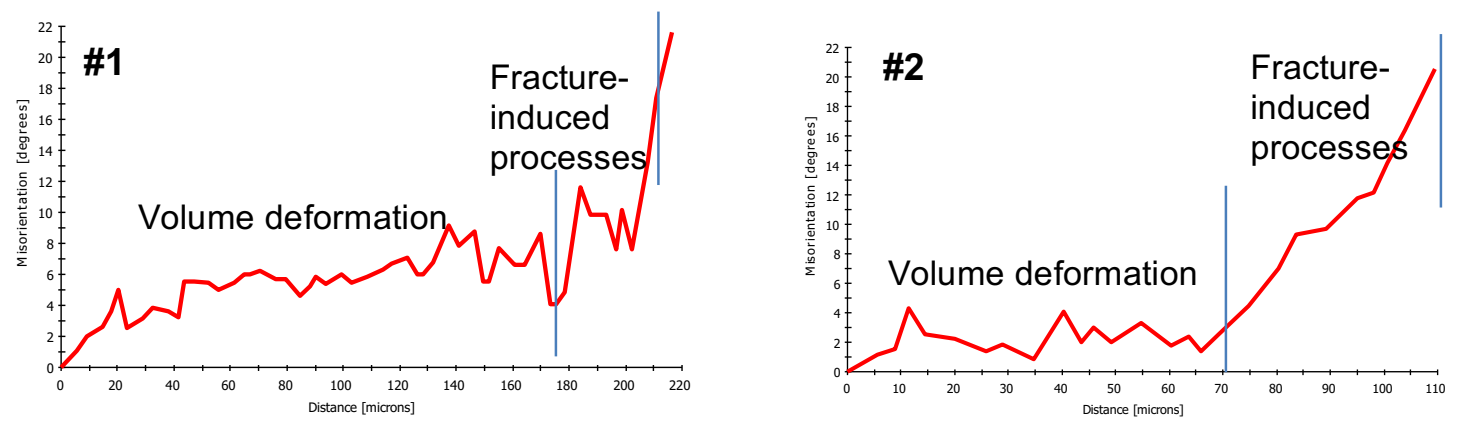

Figure 17. Misorientation profiles (point-to-origin type) showing a strong change in grain orientation near the fracture point.

\subsubsection{Defects and Anomalies}

All tensile specimens were carefully examined for anomalies in exterior and surface appearance and preexisting defects. In general, the produced raw materials (ingots, bullets, and final plates) were of high quality; a very limited number of defects and anomalies were observed, with a typical issue being coldwork-induced flaws (Figure 18). In this particular case, the defect was not observed before mechanical testing and became visible only after the test. Usually, the flaw-like defects opened under load, resulting in long, narrow cracks oriented in the straining direction (i.e., the rolling direction). Most likely, ultrasonic nondestructive inspection of the raw plates would easily reveal such defects during commercial manufacturing. 

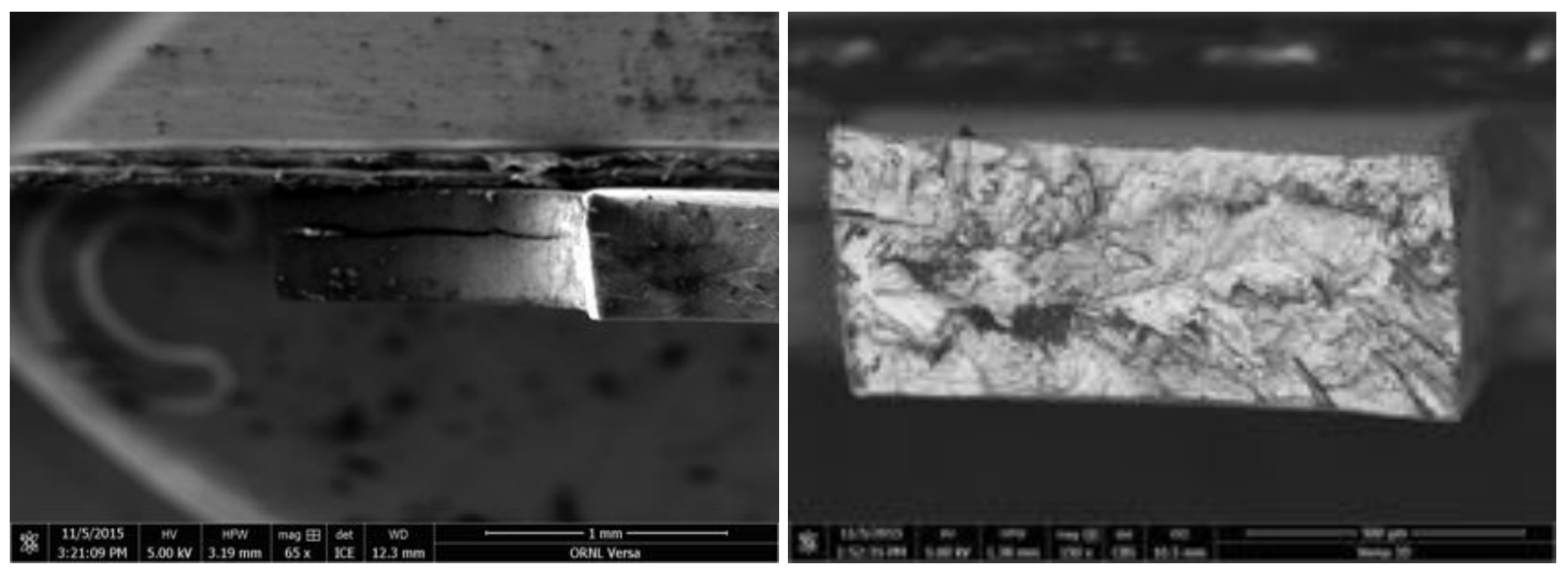

Figure 18. The internal flaw in one of the tensile specimens (ID: VW25, C37M after welding).

\subsection{TRUE STRESS-TRUE STRAIN CURVES}

\subsubsection{As-received Materials}

The true stress-true strain curves were calculated for the middle portion of the tensile specimens, far from the grips. Necking was excluded from the analysis in most cases to avoid the contribution of a complex stress state. As follows from the data (Figure 19), the true curves for the different materials were comparable, except those for the C35MN alloy, which demonstrated a significantly higher strength level than all of the other investigated alloys. The other alloys showed relatively weak differences with only minor alloying-related peculiarities. After yielding, specimens showed a smooth and monotonic deformation hardening typical for simple ferritic alloys.

The largest difference was the peculiarity in the low-strain area. Most of the materials demonstrated a weak change in hardening behavior, similar to a yield plateau, whereas the $\mathrm{C} 37 \mathrm{M}$ alloy showed monotonic hardening without any signs of a plateau. Taking into account that the studied materials were in a partly recrystallized condition, this peculiarity at low strain may be attributed to grain size and/or recrystallization degree; alloying may play a secondary role. Yield plateau at small strains is a typical feature for many BCC alloys. Its appearance depends on grain size, cold work degree, light alloying elements (carbon, nitrogen), and other characteristics. 


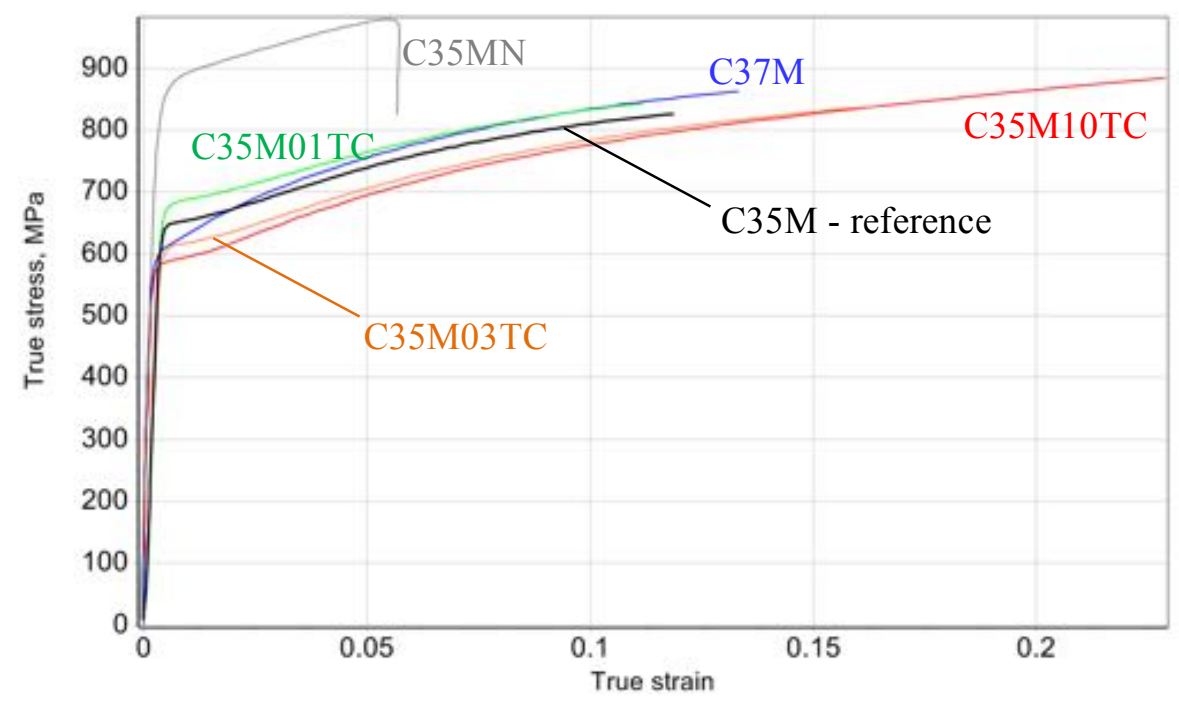

Figure 19. Typical true stress-true strain curves for the investigated alloys.

The elastic strain was not excluded.

No observed true stress-true strain curve demonstrated strain softening, i.e., a decrease in the acting stress while the strain increased. Strain softening in combination with deformation band formation is often observed in BCC materials; it depends on structural conditions and may be suppressed in cold-worked materials.

Thus, based on the available data, the conclusion may be that the variations in Al content and addition of $\mathrm{TiC}$ did not lead to significant changes in material mechanical behavior. The only exception was $\mathrm{C} 35 \mathrm{MN}$ with niobium addition; this modification led to higher yield stress (discussed earlier). Detailed analysis of the true curves may be conducted using conventional constitutive equations, like Hollomon's or Swift's equations, or modern dislocation theory approaches like the one offered in Patra and McDowell [15]. This aspect is not discussed in the present report.

\subsubsection{Local Mechanical Behavior in the Weldment}

The specimen after welding is a complex object consisting of multiple areas with different properties: weldment, HAZs, and parent (reference) material. Both the weldment and the HAZs are usually nonuniform and may have property gradients. DIC is an appropriate tool for detecting and analyzing these changes if they occur. Using DIC, any specimen location may be considered a "virtual strain gauge" allowing for local strain calculations.

Currently, in discussing weldment mechanical behavior, it seems reasonable to select the weldment center, which is usually coincident with the area of maximum strain. Figure 20 shows a typical strain distribution along the gauge of the tensile specimen. The strain maximum is close to the gauge center. 


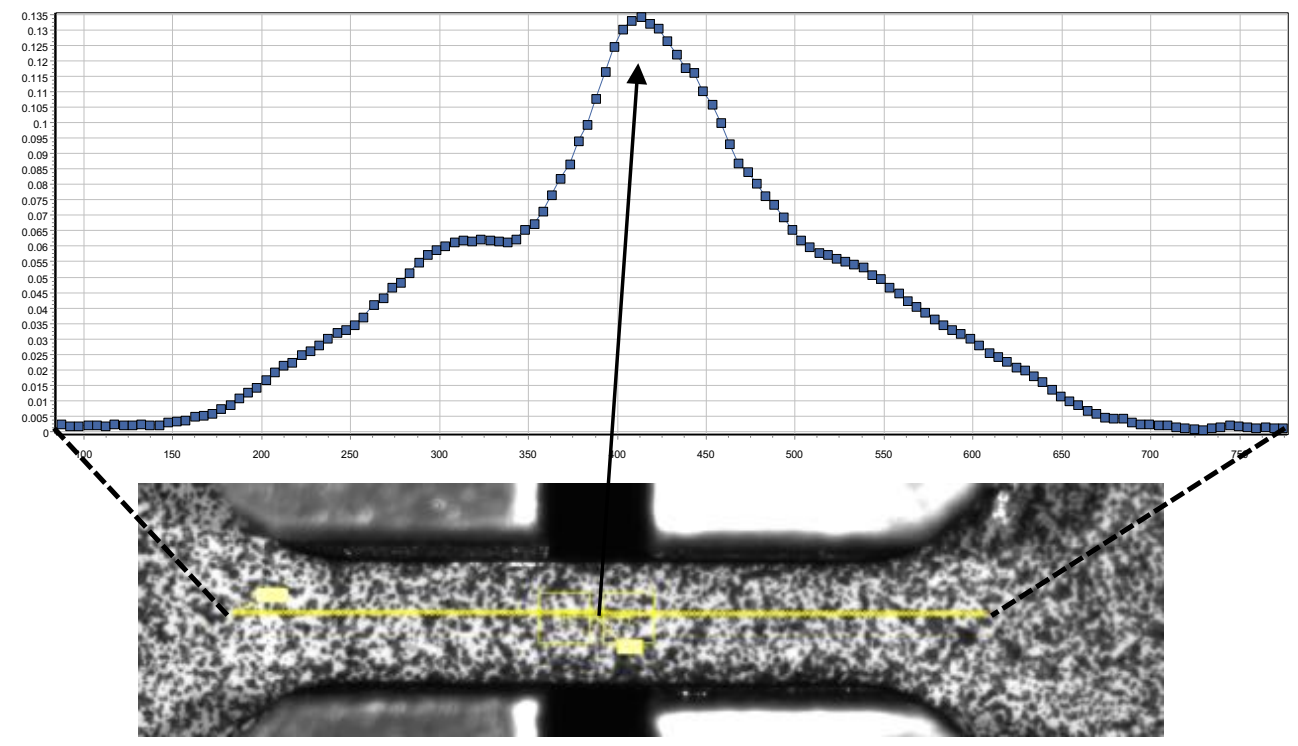

Figure 20. Strain distribution along the C37M alloy specimen gauge before fracture; welded specimen (VW24) (Green-Lagrange strain tensor). The local true stress-true strain curve was calculated for the maximum strain area (the center of the weldment).

Figure 21 demonstrates an average true stress-true strain curve for the weldment center compared with the data for the as-received (unwelded) specimen. Based on the results, the curves are very similar, with welding resulting in a reduction in the acting stress (weld-induced softening) at $\sim 130-150 \mathrm{MPa}$. The difference between the curves is almost the same within the analyzed strain range. It appears that welding led to recrystallization, grain growth, and softening, whereas the strain-hardening behavior remained virtually unaffected.

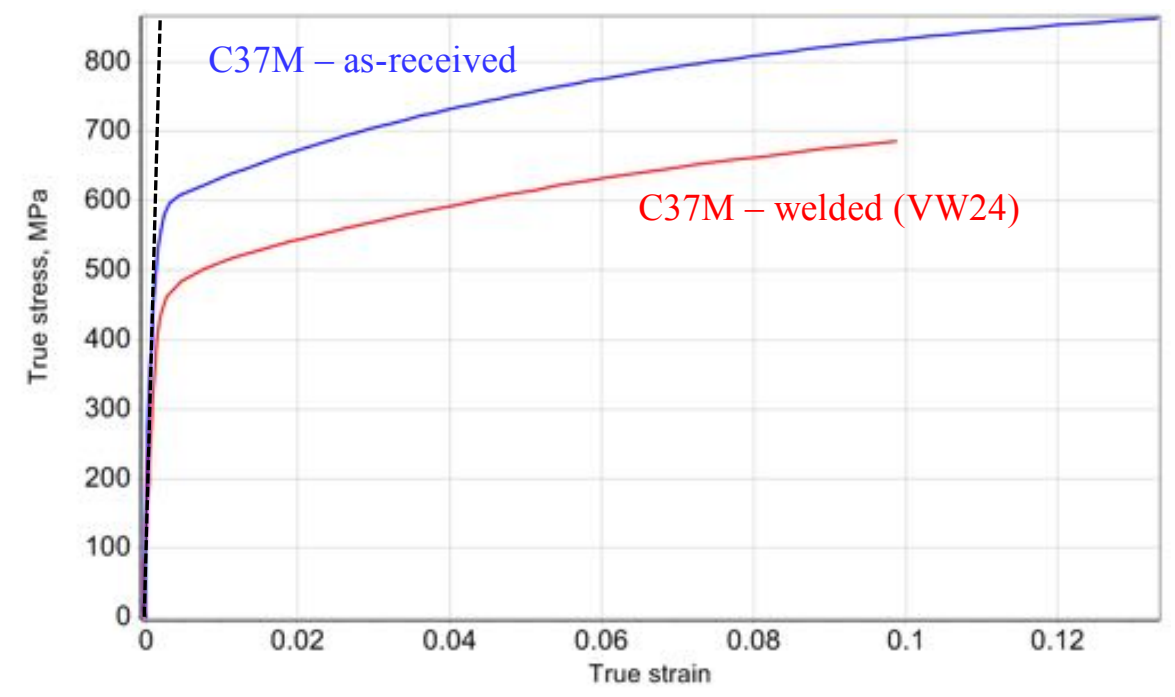

Figure 21. True strain-true stress curves for C37M alloy before and after welding. Dashed line shows elastic strain. 
Figure 22 shows the strain distribution along the gauge for one of the TiC-branch alloys, and Figure 23 demonstrates typical true stress-true strain curves for the as-received and welded specimens. All welded specimens demonstrated welding-induced softening with yield stresses of around $500 \mathrm{MPa}$. For the first two alloys, the strain-hardening behavior of the weldment was close to that of the parent material.

However, alloys with $1 \% \mathrm{TiC}$ had a significantly higher hardening rate. At $\varepsilon \sim 0.1$, the acting stress was close for as-received and welded specimens.

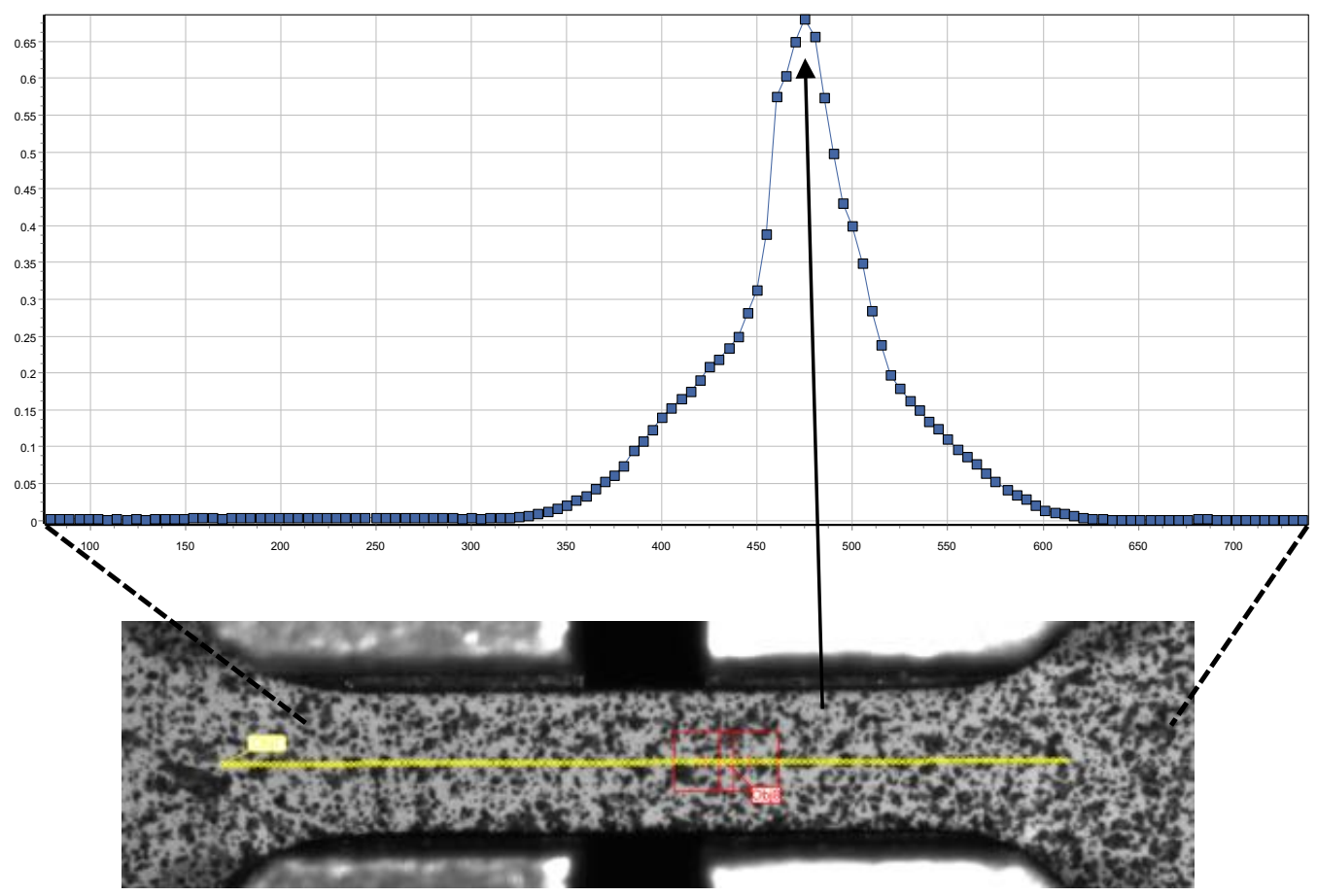

Figure 22. Strain distribution along the C35M01TC (TiC-branch) alloy specimen gauge; welded specimen (VW24) (Green-Lagrange strain tensor). Local true stress-true strain curve was calculated for the maximum strain area (the center of the weldment). 

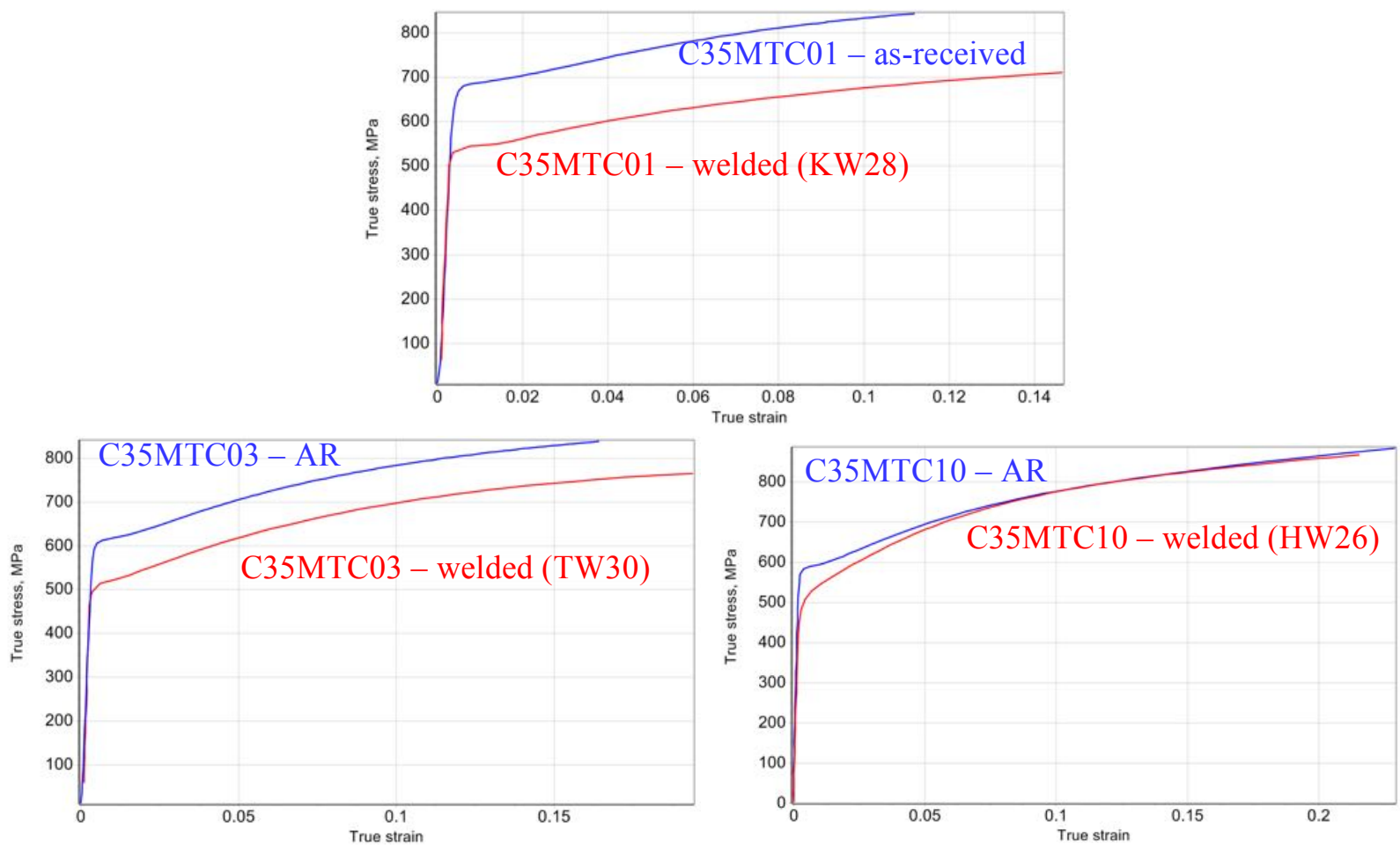

Figure 23. True strain-true stress curves for TiC-branch alloys before and after welding.

\section{CONCLUSIONS AND PERSPECTIVES}

The detailed mechanical testing reported here, as well as the microstructural characterization reported previously [11], provides some initial insights into the general weldability and overall performance of the selected candidate materials for this study.

First, generally speaking, the use of the two different alloying branches did not significantly impact the as-received or non-welded properties of the alloys. The mechanical behavior, in either engineering or true form, showed consistent behavior typical of high-Cr BCC ferritic alloys. The microstructure varied depending on the alloying branch in the as-received state but this effect was expected because of the intentional inclusions of precipitates or variations in production processes.

Second, autogenous bead-on-plate laser-based welding did not show obvious (i.e., upon naked eye inspection) flaws or other concerns in or around the weld bead. Detailed mechanical tests showed that welding leads to a decrease in the overall strength, with a softening parameter ranging from 10 to $35 \%$. This loss of strength can be attributed to discrete changes in microstructure. The alloy with the largest weld-induced softening, C35MN, most likely experienced significant recrystallization, although further work is needed to make a determination. The alloy with the lowest softening, C35M10TC, was shown to have smaller grain sizes and tortuous grain boundaries caused by the addition of TiC particles [11], indicating that alloy modifications can change the performance of $\mathrm{FeCrAl}$ weldments. Even though alloy modifications can change the overall performance, at least with respect to the changes in yield strength, it appeared that, after welding, the general mechanical response remained unchanged. Most alloys showed typical yielding followed by necking, and the general shapes of the engineering and true curves remained similar to those of the curves shown for the as-received state. 
Third, the most detrimental effect observed in the weldments was sudden fracture events, which were deviations from the typical behavior of the tested lot of weldments. These sudden fracture events resulted in extreme losses in ductility and in some cases indicated a nearly full brittle fracture in the alloy. Investigation into these events showed that small defects, such as porosity or inclusions not eliminated during manufacturing, were probably the root cause of the fractures.

Based on these observations, it can be concluded that benefits to weldability can be derived from modification of FeCrAl alloys. Because of the random nature of defect inclusions and the observed sudden fracture response, it was difficult to conclude whether one alloy modification is better than another at the time of this report. However, an effort to do so was made. Clearly, the base alloy still performs in an acceptable manner and should and will continue to be investigated in the program. The C35M10TC alloy also shows interesting properties, including the response after irradiation due to the retention of smaller grain sizes within the fusion zone, and remains a high-value alloy for investigation. Based on its observed degree of softening, along with the presence of brittle/cleavage type fractures, $\mathrm{C} 35 \mathrm{MN}$ is the lowest-priority alloy of interest at this time. The higher-Al variants, $\mathrm{C} 36 \mathrm{M}$ and $\mathrm{C} 37 \mathrm{M}$, remain of interest primarily to determine the effect of $\mathrm{Al}$ on the radiation tolerance of $\mathrm{FeCrAl}$ alloys. Based on these assessments, a pure down-selection of alloys cannot be determined; but a general prioritization of examination for further studies can be determined and is as follows (listed in order of priority): C35M, C3510TC, C37M, C35M03TC, C35M01TC, C36M, and C35MN.

\section{REFERENCES}

[1] B.A. Pint, K.A. Terrani, M.P. Brady, T. Cheng, J.R. Keiser, High temperature oxidation of fuel cladding candidate materials in steam-hydrogen environments, J. Nucl. Mater. 440 (2013) 420 427. doi:10.1016/j.jnucmat.2013.05.047.

[2] K.A. Terrani, S.J. Zinkle, L.L. Snead, Advanced oxidation-resistant iron-based alloys for LWR fuel cladding, J. Nucl. Mater. 448 (2013) 420-435. doi:10.1016/j.jnucmat.2013.06.041.

[3] B.A. Pint, K.A. Unocic, K.A. Terrani, The effect of steam on the high temperature oxidation behavior of alumina-forming alloys, Mater. High Temp. 32 (2014) 28-35.

[4] Y. Yamamoto, B.A. Pint, K.A. Terrani, K.G. Field, L.L. Snead, Development and property evaluation of nuclear grade wrought $\mathrm{FeCrAl}$ fuel cladding for light water reactors, AcceptedJ. Nucl. Mater. (2015).

[5] E.A. Little, D.A. Stow, Void-swelling in irons and ferritic steels, J. Nucl. Mater. 87 (1979) 25-39.

[6] K.G. Field, X. Hu, K.C. Littrell, Y. Yamamoto, L.L. Snead, Radiation tolerance of neutronirradiated model Fe-Cr-Al alloys, J. Nucl. Mater. 465 (2015) 746-755. doi:10.1016/j.jnucmat.2015.06.023.

[7] P.D. Edmondson, S.A. Briggs, Y.Yamamoto, R.H. Howard, K. Sridharan, K.A. Terrani, et al., Irradiation-enhanced $\alpha^{\prime}$ precipitation in model FeCrAl alloys, Scr. Mater. 116 (2016) 112-116. doi:10.1016/j.scriptamat.2016.02.002.

[8] J.R. Regina, J.N. Dupont, A.R. Marder, The effect of chromium on the weldability and microstructure of Fe-Cr-Al weld cladding, Weld. J. 86 (2007) 170-178.

[9] J.N. Dupont, J.R. Regina, K. Adams, Improving the weldability of FeCrAl weld overlay coatings, Foss. Energy Mater. Conf. (2007) 131-137.

[10] S. Kobayashi, T. Takasugi, Mapping of $475^{\circ} \mathrm{C}$ embrittlement in ferritic $\mathrm{Fe}-\mathrm{Cr}-\mathrm{Al}$ alloys, Scr. Mater. 63 (2010) 1104-1107. doi:10.1016/j.scriptamat.2010.08.015. 
[11] K.G. Field, M.N. Gussev, R. Howard, First Annual Progress Report on Radiation Tolerance of Controlled Fusion Welds in High Temperature Oxidation Resistant FeCrAl Alloys, ORNL/TM2015/770. (2015).

[12] K.G. Field, M.N. Gussev, Y. Yamamoto, X. Hu, R.H. Howard, Preliminary Studies on the Fabrication and Characterization of Fe-Cr-Al Alloys Designed to Have Enhanced Weldability and Radiation Tolerance, ORNL/TM-2015/192. (2015).

[13] K.G. Field, M.N. Gussev, X. Hu, Y. Yamamoto, Preliminary Results on FeCrAl Alloys in the Asreceived and Welded State Designed to Have Enhanced Weldability and Radiation Tolerance, ORNL/TM-2015/579. (2015).

[14] K.G. Field, R.H. Howard, Y. Yamamoto, Design of Experiment for Irradiation of Welded Candidate Fe-Cr-Al Alloys, ORNL/TM-2015/375. (2015).

[15] A. Patra, D.L. McDowell, Crystal plasticity investigation of the microstructural factors influencing dislocation channeling in a model irradiated bcc material, Acta Mater. 110 (2016) 364-376. doi:10.1016/j.actamat.2016.03.041. 